\title{
Design of Linear Functional Noncircular Gear with High Contact Ratio Used in Continuously Variable Transmission
}

\section{Ya-Nan Hu}

State Key Laboratory of Mechanical Transmission

Chao Lin ( $\sim$ linchao@cqu.edu.cn )

State Key Laboratory of Mechanical Transmission

Chun-Jiang He

State Key Laboratory of Mechanical Transmission

Yong-Quan Yu

State key laboratory of Mechanical Transmission

\section{Zhi-Qin Cai}

Xiamen University

\section{Original Article}

Keywords: Continuously variable transmission, Noncircular gear, Pitch curve, Contact ratio, Contact tooth profile

Posted Date: November 24th, 2020

DOI: https://doi.org/10.21203/rs.3.rs-113061/v1

License: (c) (1) This work is licensed under a Creative Commons Attribution 4.0 International License. Read Full License 


\section{Title page}

\section{Design of Linear Functional Noncircular Gear with High Contact Ratio Used in Continuously Variable Transmission}

Ya-Nan Hu, born in 1993, is currently a PhD candidate in the State Key Laboratory of Mechanical Transmission, Chongqing University, China. From September, 2016 to now, she have been studying in Chongqing University for her master's and doctor's degree. Her research interests include theoretical research and application design of non-circular gear and curve-face gear composite transmission.

E-mail: 20160702030@cqu.edu.cn

Chao Lin, born in 1958, Ph.D., is a professor and doctoral supervisor of the College of Mechanical Engineering / the State Key Laboratory of Mechanical Transmission, Chongqing University, China. His research interests include meshing theory of spiral bevel gears, noncircular gears and new gear transmission, and precision transmission and drive.

Tel: +86-13452911958; E-mail: linchao@cqu.edu.cn

Chun-Jiang He, born in 1992, received the B.S. degree in mechanical engineering from Chongqing University, China, in 2011, and Ph.D. degree in mechanical engineering from Chongqing University, China, in 2020. Now, he is a Lecturer at the School of Mechanical and Power Engineering, Chongqing University of science and technology, University. His research interests include intelligent design and manufacturing.

E-mail: 20112407@cqu.edu.cn

Yong-Quan Yu, born in 1994, received the B.S. degree in mechanical engineering from Hefei University of Technology, Hefei, in 2016. $\mathrm{He}$ is currently pursuing the Ph.D. degree in mechanical engineering at Chongqing University, Chongqing, China. His research interests include the development of the new type of gear transmission, fundamental study of curve-face gear, and surface topography of noncircular gear.

E-mail: 20160702017@cqu.edu.cn

Zhi-Qin Cai, born in 1988, is a lecturer at the School of Aeronautics and Astronautics, Xiamen University. He received his PhD in mechanical engineering from Chongqing University. His research interests include intelligent design of precision gear driven by shape coupling, micro-texture of tooth surface, and energy-saving transmission design.

E-mail: caizhiqin@xmu.edu.cn

\section{Corresponding author: Chao Lin E-mail: linchao@cqu.edu.cn}




\title{
Design of Linear Functional Noncircular Gear with High Contact Ratio Used in Continuously Variable Transmission
}

\author{
Ya-Nan Hu ${ }^{1} \cdot$ Chao Lin $^{1} \cdot$ Chun-Jiang He $^{1} \cdot$ Yong-Quan Yu $^{1} \cdot$ Zhi-Qin Cai $^{2}$
}

Received June xx, 201x; revised February xx, 201x; accepted March xx, 201x

(C) Chinese Mechanical Engineering Society and Springer-Verlag Berlin Heidelberg 2017

\begin{abstract}
Continuously variable transmission (CVT) of noncircular gears has the technical advantages of large bearing capacity and high transmission efficiency. This paper focuses on the linear functional noncircular gear pair to realize continuously variable transmission. According to the required working section transmission ratio of noncircular gear pair, the transmission ratio function in the non-working section, was constructed by using polynomial, and then the influence of pitch curve parameters in working section on which in non-working section was also analyzed. Furthermore, the pitch curve of the linear functional noncircular gear pair, which are suitable for transmission, were obtained. In order to improve the stability and bearing capacity of gear transmission, the noncircular gear pair transmission with high contact ratio was designed, and an indirect method to verify the contact ratio by detecting the contact length error of tooth profile was proposed. The error was calculated by comparing the actual contact tooth profile length obtained from the rolling experiment with the accurate value of contact tooth profile length based on the principle of gear and the property of involute profile, and the noncircular gear transmission with high contact ratio was verified. Keywords: Continuously variable transmission $\bullet$ Noncircular gear - Pitch curve $\bullet$ Contact ratio $\bullet$ Contact tooth profile
\end{abstract}

\section{Introduction}

Although continuously variable transmission (CVT) technology has been used in vehicles for only several decades, its advantages over traditional transmission are obvious: it has a wider range of working speed ratio; and it is easier to form an ideal match with the engine, so as to improve the combustion process, and further reduce fuel

Chao Lin

linchao@cqu.edu.cn

The State Key Laboratory of Mechanical Transmission, Chongqing University, Chongqing 400044, China consumption and emissions; it has high transmission efficiency, less power loss and high economy(Jian \& Chau, 2010). Generally, three main transmission modes can be adopted to realize infinitely variable speeds, namely, liquid transmission, electric transmission and mechanical transmission. Different from the liquid transmission mode with a higher sliding rate, and the electric transmission mode with lower efficiency and unstable operation at low speed, in this respect, mechanical continuously variable transmission can easily realize effective transmission among three modes under special work conditions, such as high load, due to the equipment of more compact structure (Ruan, 1983).

The transmission mechanism of mechanical CVT mainly includes belt transmission (Toru et al., 1993), chain transmission (Yildiz et al., 2016), and gear transmission (Chen et al., 2017). Nevertheless, belt CVT and chain CVT are the most common CVTs used in vehicles due to their simple structure, small size and light weight (Machida et al., 1995). Despite these advantages, their limited torque capacity and low transmission efficiency cannot be ignored.

With the development of noncircular gear design and manufacturing technology, and combined with the characteristics of noncircular gear transmission with nonuniform speed ratio transmission, which belongs to conjugate meshing transmission (Litvin et al., 2008)(Li, 1983)(Wu \& Wang, 1997), continuously variable transmission can be realized by using the transmission characteristics of noncircular gear, which is expected to improve the power and torque transmitted (Litvin \& Fuentes, 2004).

Many scholars have done a lot of research on the

The School of Aeronautics and Astronautics, Xiamen University, Xiamen 361005, China 
transmission technology of noncircular gears, which has gradually solved many problems of noncircular gears, such as, the geometric design of pitch curve, the configuration and processing of gear teeth. And the transmission technology of noncircular gear pair has entered a new practical period (Sun et al., 2015). D. Dooner (Dooner et al., 1998) recommended a continuously variable device of noncircular gears with serrated transmission ratio. CVT could be realized within specified range when controllable phase shift and planetary additive differential were used between noncircular gear devices (Ferguson et al., 1975). Emura and Arakawa (Emura \& Arakawa, 1992) utilized a non-circular gear for steering mechanism analysis. The pitch curves also have sharp points that require complex modification, but can be continuous if the design is reasonable. Among them, the range of transmission ratio of the adder is limited. While the subtractor has power cycle, its range of transmission ratio is arbitrary (Litvin, Faydor L et al., 2009). F.Y. Zheng (Zheng et al., 2016) put forward a new application of noncircular gears, which is an indexing mechanism using noncircular gears. F. Y. Zheng (Zheng et al., 2018) also provided a new generation method for noncircular gear, through which the generated gear may embody advantages of localized tooth contact and good lubrication in practice. Based on the gear with rack and geared segment, Petre Alexandru (Alexandru et al., 2012) presented the geometric and functional characteristics of a gear with ascending variable ratio. This gear can be used for the steering boxes of some low power vehicles (without servo-system). Detailed descriptions of the gear trains for tracking the motions of the Mercury planet and of the Moon are herein presented by Addomine $\mathrm{M}$ (Addomine et al., 2018). In these gear trains noncircular gears have been used to account for the apparent irregular motion of the planets.

The contact ratio of gear transmission is closely related to the mesh stiffness, which is an important parameter of gear transmission design and analysis (Tang et al., 2014). As an index to measure the bearing capacity and transmission smoothness of gears, the higher the contact ratio is, the better the transmission smoothness is (Wu \& Wang, 1997). This paper mainly started with required transmission ratio, and the influence of linear functional working pitch curve parameters on the non-working pitch curve is studied. The parameters of the linear functional noncircular gear pair suitable for transmission are obtained. An indirect method to verify the contact ratio by detecting the contact length error of tooth profile is proposed, and the high contact ratio of noncircular gear pair is verified. The research in this paper contributes to reducing transmission chain and simplifying noncircular gear design using for CVT.

\section{Design of Pitch Curve of Noncircular Gear in CVT}

\subsection{Realization of infinitely variable transmission using noncircular gears}

Constant transformation from input shaft to output shaft can be realized by continuously variable noncircular gear transmission through continuous and alternating transmission of power in the range of 0 to $360^{\circ}$ by the multi branch loop, realizes, to obtain a constant speed ratio. Each branch loop is a three-element planetary row for differential coupling of two-order parallel noncircular gear pairs with non-uniform output speed, and then the constant speed ratio within a certain angle range is obtained through controllable overrunning clutch. Rotation shafts of this branch are free rotation without power transmission, ranging in other rotation angle. Accordingly, speed ratio can be continuously adjusted by changing the phase angle of two parallel noncircular gear pairs. The continuously variable noncircular gear transmission system model and skeleton of scheme mechanism are shown in Figure.1.

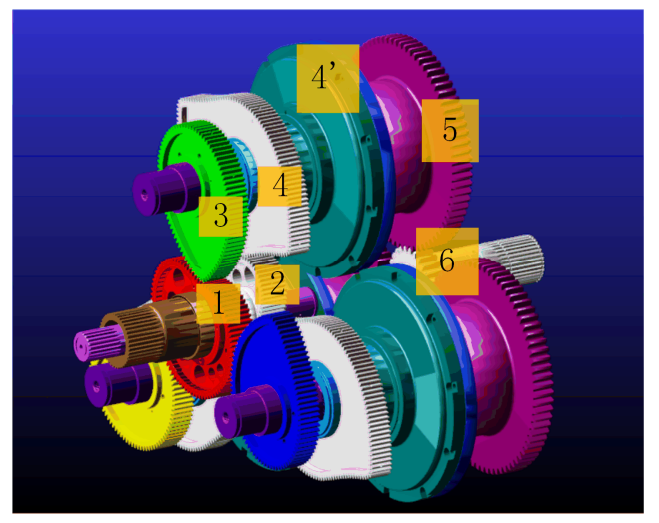

(a) System model

$$
\begin{aligned}
& \text { The double-row } 2 \mathrm{~K}-\mathrm{H} \\
& \text { epicyclic gear train }
\end{aligned}
$$

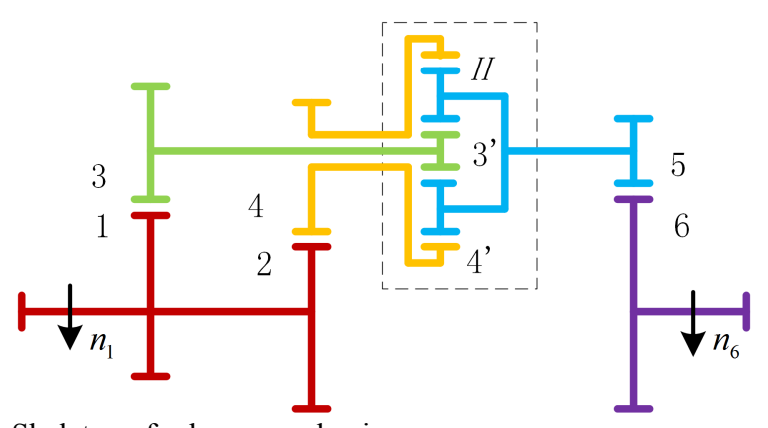

(b) Skeleton of scheme mechanism

Figure 1. Continuously variable noncircular gear transmission 
As shown in Figure. 1, gear pairs 1-3 and 2-4 are noncircular gear pairs, while the rest are cylindrical gear pairs. This system with a constant transmission ratio involves the transmission unit superposition of two branch noncircular gear pairs with variable phase. During working process, a constant velocity input of component 1 will be transformed into the velocity output with linear function of component $\mathbf{3}$ and component 4, through the first level transmission of noncircular gear pair. And the constant output speed can be obtained in a limited range of angle, after the output speed of component $\mathbf{3}$ and $\mathbf{4}$ is differential coupling. It is noted that the single-branch noncircular gear pair unit can only achieve stable speed at a limited angle. Once three-branch second-order noncircular gear pair is properly arranged around the central axis, with the minimum working angle of each branch during per cycle being $120^{\circ}$, as a result, constant velocity output will be obtained during random angle range.

In transmission system, gear $\mathbf{1}$ and gear $\mathbf{2}$ are fixed on the input shaft, and transmission ratios $m$ of noncircular gear pair 1-3 and 2-4 in working section $[0, t]$ are

$$
\begin{gathered}
m_{31}=\frac{\omega_{3}}{\omega_{1}}=f\left(\theta_{1}\right)=k_{1} \theta_{1}+b_{1} \quad \theta_{1} \in[0, t] \\
m_{42}=\frac{\omega_{4}}{\omega_{2}}=g\left(\theta_{1}\right)=k_{2}\left(\theta_{1}-\theta\right)+b_{2} \quad \theta_{1} \in[0, t]
\end{gathered}
$$

Where, $\theta_{1}$ is the rotational angle of gear $\mathbf{1}$ and gear $2 . \quad$ is the phase angle between gear 1 and gear 2 , and $t$ is maximum rotational angle at working section in a period; $k$ and $b$ represent the slope value and the intercept value of linear function respectively.

By designing the double-row $2 \mathrm{~K}-\mathrm{H}$ type epicyclical gear train with specific number of teeth, the following relation can be achieved:

$$
m_{61}=m\left(k_{1} \theta_{1}+b_{1}\right)+n\left(k_{2} \theta_{2}+b_{2}\right)=c
$$

When a fixed speed is inputted by shaft 1 , shaft 6 will output a constant speed, and the rotation speed of each level in gear transmission system are shown in Figure.2.

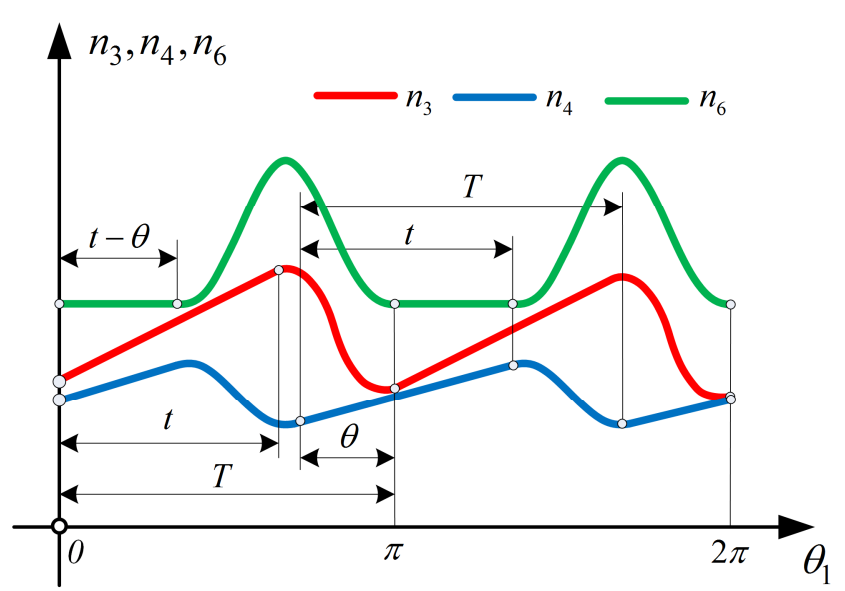

(a) Gear velocity at all levels in continuously variable noncircular gear transmission

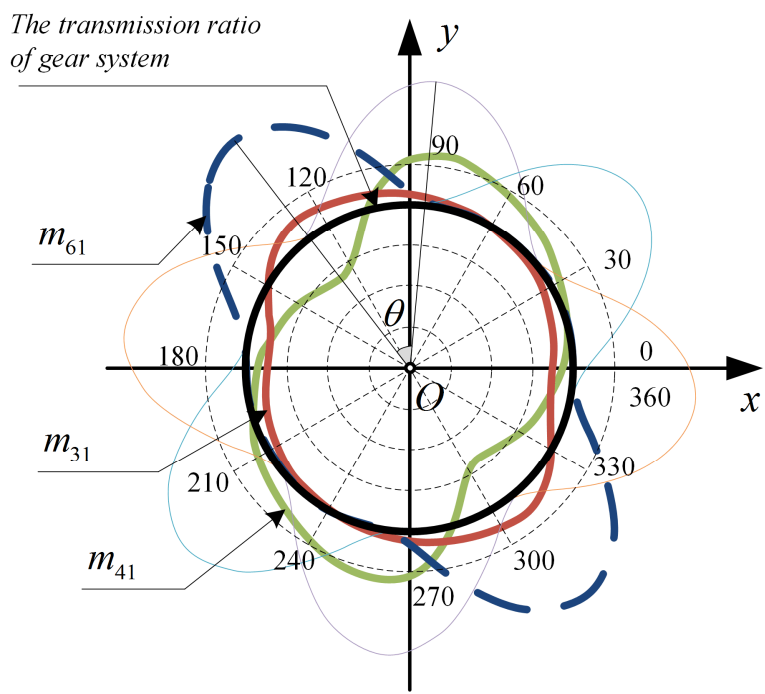

(b) The transmission ratio of each level in continuously variable noncircular gear transmission

Figure 2 The basic transmission characteristics of continuously variable noncircular gear transmission

As shown in Figure. 2, continuously variable velocity is realized at phase angle $\theta$ by using the second-order noncircular gear pair. The constant rotation speed can be outputted by output shaft $\mathbf{6}$, as the phase angle between two noncircular gear pairs is $\theta$. And the wider range of constant rotation speed output is achieved during each period with decreased phase angle $\theta$.

\subsection{Transmission Ratio of Noncircular Gear in Non- working Section}

Obviously, the pitch curve of noncircular gear is different at two sections during a period, that is, the transmission ratio is in the form of a linear function in working section or that presents a complex curve in non-working section. Polynomial is used to construct the transmission ratio 
function of the non-working section outside the given interval in a transmission ratio period. Supposing the transmission ratio of noncircular gear pair in one period is expressed as follow.

$$
m_{31}=\frac{n_{3}}{n_{1}}= \begin{cases}m_{1}\left(\theta_{1}\right)=k_{1} \theta_{1}+b_{1} & \theta_{1} \in[0, t] \\ m_{2}\left(\theta_{1}\right)=\sum_{i=0}^{6}\left(a_{i} \theta_{1}^{i}\right) & \theta_{1} \in(t, T]\end{cases}
$$

And, $a_{i}$ is the polynomial coefficient. The first-order and second-order noncircular gear is driving and driven parts, respectively. It is reported by Huang (Huang \& Lan, 2011), the values of $a_{i}(i=1, \ldots ., 7)$ can be calculated by 7 independent equations including 1 closed condition and 6 boundary conditions, which is shown in (5).

$$
\left\{\begin{array}{l}
\int_{t}^{T} m_{2}\left(\theta_{1}\right) d \theta_{1}=\frac{2 \pi}{n_{2}}-\int_{0}^{t} m_{1}\left(\theta_{1}\right) d \theta_{1} \\
m_{1}(t)=m_{2}(t) \\
m_{1}^{\prime}(t)=m_{2}^{\prime}(t) \\
m_{1}^{\prime \prime}(t)=m_{2}^{\prime \prime}(t) \\
m_{1}(0)=m_{2}(T) \\
m_{1}^{\prime}(0)=m_{2}^{\prime}(T) \\
m_{1}^{\prime \prime}(0)=m_{2}^{\prime \prime}(T)
\end{array}\right.
$$

And so far, the transmission ratio of noncircular gear pair in the first period has been determined.

\subsection{Influence Parameters of Pitch Curve of Noncircular Gear Pair}

Due to the pitch curves form of two noncircular gear pairs are same as (4) but some parameters are discrepant. Then, the transmission characteristics of noncircular gear pair with linear functional transmission ratio is discussed basing on the example of gear pairs 1-3. The pitch curve of noncircular gear pair can be obtained according to the centrode. In the working section $\theta_{1} \in[0, t]$, the radius vector of the pitch curve, including driving gear and driven gear, can be expressed as:

$$
\begin{gathered}
r_{1}\left(\theta_{1}\right)=E \frac{m_{21}}{m_{21}+1}=E \frac{k_{1} \theta_{1}+b_{1}}{k_{1} \theta_{1}+b_{1}+1} \\
\left\{\begin{array}{l}
r_{2}\left(\theta_{1}\right)=E-r_{1}\left(\theta_{1}\right)=\frac{E}{k_{1} \theta_{1}+b_{1}+1} \\
\theta_{2}\left(\theta_{1}\right)=\int_{0}^{\theta_{1}}\left(k_{1} \theta+b_{1}\right) d \theta=\frac{k_{1}}{2} \theta_{1}^{2}+b_{1} \theta_{1}
\end{array}\right.
\end{gathered}
$$

Where, $r_{1}\left(\theta_{1}\right)$ is the radius vector of driving gear, which numbered 1. $r_{2}\left(\theta_{1}\right)$ is the radius vector of driven gear, which numbered 2. And $\theta_{2}\left(\theta_{1}\right)$ is the rotational angle of driven gear. The center distance between two gears is $E$. $k_{1}$ and $b_{1}$ are slope and intercept of linear function section in transmission ratio, respectively. According to (5), $k_{1}$ and $b_{1}$ are important parameters of transmission ratio curve in nonworking section. By analyzing the influence of the parameters $k_{1}$ and $b_{1}$ on the pitch curve in non-working section of noncircular gear pair with linear functional transmission ratio, the optimal pitch curve can be acquired.

1) The influences of parameter $b_{1}$ on transmission ratio of noncircular gear pair, when $k_{1}$ is constant.

Taking 1-3 gear pairs as an example, the value of period $T$ is $\pi$, and the maximum rotational angle $t$ in working section during a period is $2 / 3 \pi$. When $k_{1}$ is $3 / 4 \pi$, the influence of parameter $b_{1}$ with variable value on transmission ratio is analyzed.

As shown in Figure.3, with the value of $b_{1}$ increases in the interval of $[0.5,2.1]$, the amplitude of transmission ratio first decreased and then increased, and the transmission ratio curve in non-working section is first convex and then concave. Nevertheless, it seems clear that the transmission ratio curve changes gently with the rotation angle around the value of 1.75 for $b_{1}$, and in this situation, the instantaneous velocity and acceleration are smaller, and the minimum radius of curvature of pitch curve is larger, so it is more suitable for transmission. And the corresponding transmission ratio and pitch curve of noncircular gear pair are shown as red curve in Figure.3a) and 3b).

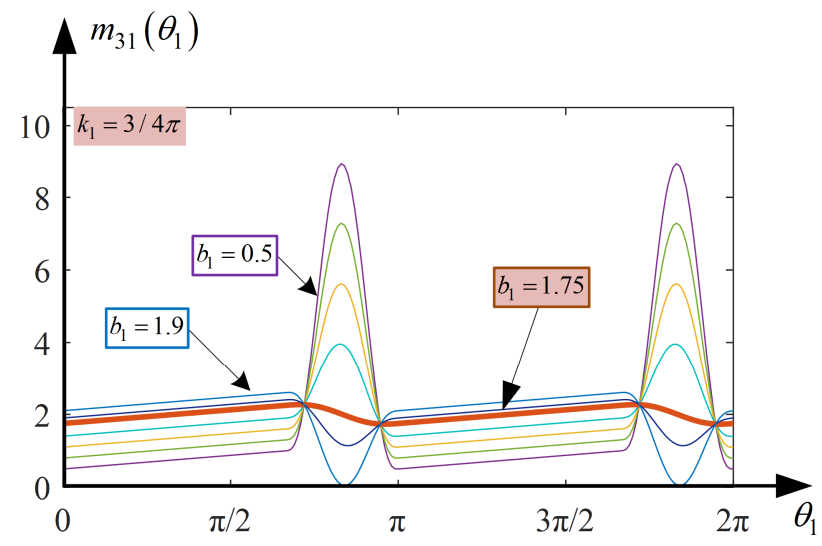

(a) The transmission ratio 


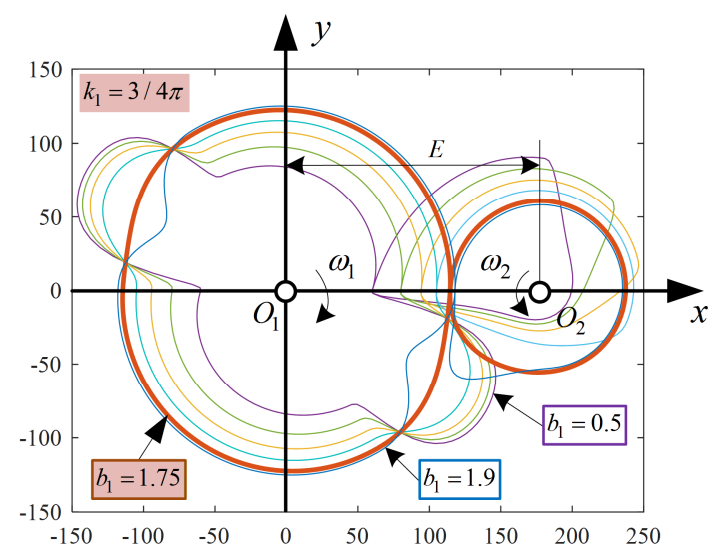

(b) The pitch curve

Figure 3 The influence of $b_{1}$ on transmission ratio of noncircular gear pair

The interval length $y$ of codomain of transmission ratio can be calculated as follow.

$$
y=m_{31 \max }-m_{31 \min }
$$

According to the above analysis, when the transmission ratio with the most appropriate obtained linear function parameter, the interval length of codomain of the transmission ratio is the narrowest. Therefore, the minimum interval length of codomain of transmission ratio under different parameters can help us to find the value of $b_{1}$ that best fits for transmission, at a certain value of $k_{1}$.

2) The influences of $k_{1}$ on transmission ratio of noncircular gear pair, when $b_{1}$ is constant.

Similarly, when $b_{1}$ is 0.5 , with different values of $k_{1}$, the influences of $k_{1}$ on transmission ratio is analyzed as shown in Figure.4.

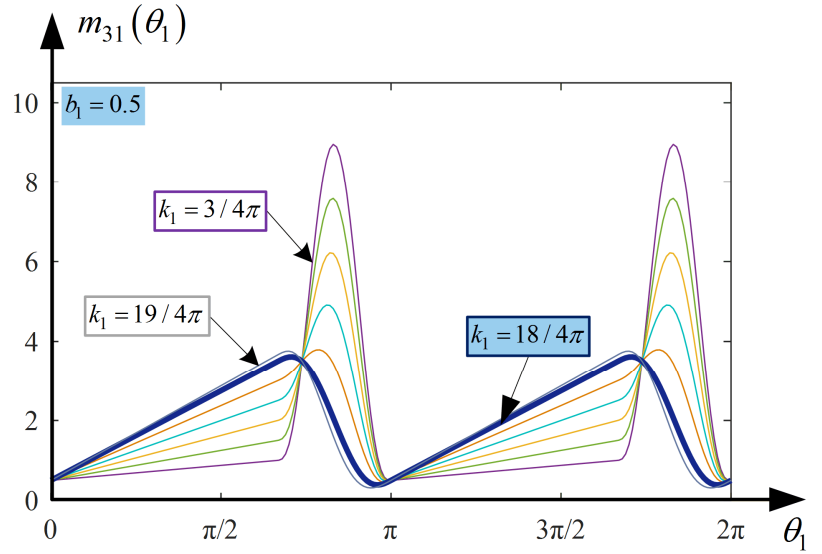

(a) The transmission ratio

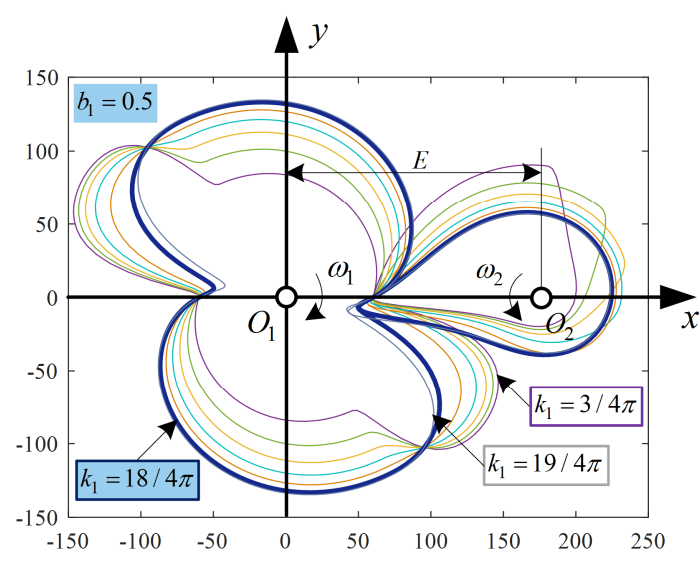

(b) The pitch curve

Figure 4 The influences of $k_{1}$ on transmission ratio of noncircular gear pair

With the increase of $k_{1}$ from $3 / 4 \pi$ to $19 / 4 \pi$, the amplitude of the transmission ratio first decreases and then increases. The transmission ratio curve in non-working section is first convex and then concave. And around the value of $9 / 2 \pi$ for $k_{1}$, the transmission ratio curve is the gentle, that is, the interval length $y$ of codomain of transmission ratio is narrow, which is suitable for transmission. While $k_{1}$ is $9 / 2 \pi$ and $b_{1}$ is 0.5 , the transmission ratio function curve is relatively smooth, and the transmission ratio and centrode of noncircular gear pair are shown as blue curve in Figure. 4 .

3) The combined influences of $k_{1}$ and $b_{1}$ on transmission ratio of noncircular gear pair

According to the above analysis, each value of $k_{1}$ must correspond to an optimal value of $b_{1}$ for transmission, so a series of values of $k_{1}$ and $b_{1}$ can be obtained. When the maximum rotational angle $\Phi_{2}$ in working section of the driven gear is equal to the product of the maximum rotational angle $\Phi_{1}$ of the driving gear and its order $n_{1}$, that is $\Phi_{2}=\Phi_{1} \times n_{1}$, the optimal transmission ratio curve of the nonworking section can be acquired. Furthermore, when the transmission ratio of the gear pair in the working section is expressed as $m_{21}=k_{1} \varphi_{1}+b_{1}$, and the transmission ratio curve of non-working section constructed by the six-order polynomial meets the condition that $k_{1} \pi+3 b_{1}=6$, the optimal transmission ratio curve in non-working section is also obtained. And now, the range of transmission ratio of noncircular gear pair in the working section is $[b, 4-b]$, in addition, with a certain value of $k_{1}, b_{1}$ is $2-(\pi / 3) k_{1}$, and the range of transmission ratio is $\left[2-(\pi / 3) k_{1}, 2+(\pi / 3) k_{1}\right]$. 


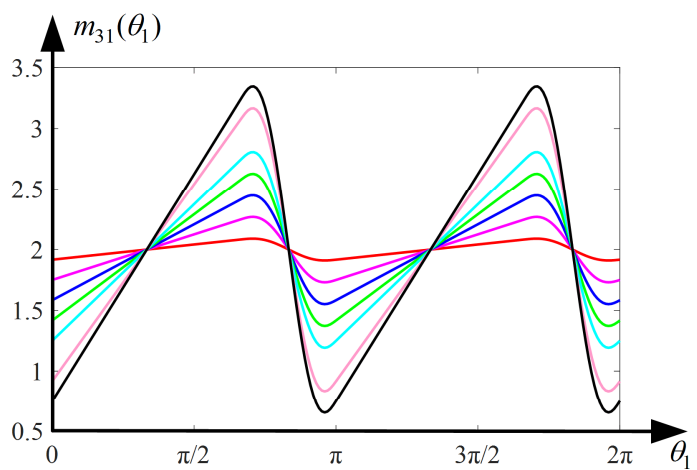

$-\mathrm{k}_{1}=7 / 4 \pi \mathrm{b}_{1}=17 / 12-\mathrm{k}_{1}=5 / 4 \pi \mathrm{b}_{1}=19 / 12-\mathrm{k}_{1}=3 / 4 \pi \mathrm{b}_{1}=21 / 12-\mathrm{k}_{1}=1 / 4 \pi \mathrm{b}_{1}=23 / 12$ - $k_{1}=15 / 4 \pi b_{1}=9 / 12-k_{1}=13 / 4 \pi b_{1}=11 / 12-k_{1}=11 / 4 \pi b_{1}=13 / 12-k_{1}=9 / 4 \pi b_{1}=15 / 12$

(a) The transmission ratio

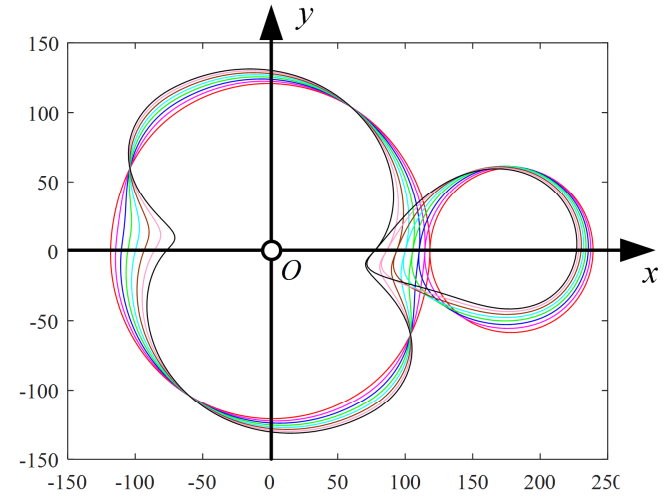

$-k_{1}=7 / 4 \pi b_{1}=17 / 12-k_{1}=5 / 4 \pi b_{1}=19 / 12-k_{1}=3 / 4 \pi b_{1}=21 / 12-k_{1}=1 / 4 \pi b_{1}=23 / 12$ $-k_{1}=15 / 4 \pi b_{1}=9 / 12-k_{1}=13 / 4 \pi b_{1}=11 / 12-k_{1}=11 / 4 \pi b_{1}=13 / 12-k_{1}=9 / 4 \pi b_{1}=15 / 12$

(b) The pitch curve

Figure 5 Comparisons of transmission ratio and centrode of noncircular gear pairs with different transmission ratio parameters

The comparison of pitch curves of noncircular gear pairs with different transmission ratio parameters is shown in Figure.5. With $k_{1}$ gradually increasing, even if the most appropriate $b_{1}$ is taken to make the minimum fluctuation of transmission ratio curve, and the transmission ratio function at this point is smooth, the minimum curvature radius of pitch curve is so small that the teeth are subjected to extra bending stress, resulting that the teeth are prone to bending and fracture, which is not suitable for transmission.

\section{The Contact Ratio of Noncircular Gear Pair}

The contact ratio of noncircular gear is the ratio between the effective meshing curve length and the pitch of gear base circle, which significantly affects the meshing performance of noncircular gear transmission. It was reported by $\mathrm{Wu}(\mathrm{Wu}$ \& Wang, 1997), the contact ratio of noncircular gear pair can be expressed as follows:

$$
\varepsilon=\frac{u_{1}+u_{2}}{\pi m \cos \alpha_{0}}
$$

Where, $u_{i}=\sqrt{\left(\rho_{i}+h_{a i}\right)^{2}-\left(\rho_{i} \cos \alpha_{0}\right)^{2}}-\rho_{i} \sin \alpha_{0}, \quad(i=1,2)$; $\rho_{1}$ and $\rho_{2}$ are the curvature radius of the pitch curve at the meshing point $P ; \alpha_{0}$ is the angle between meshing curve and the tangent of pitch curve at meshing point $P$, that is, the tooth profile angle of rack cutter.

According to (9), main parameters that affect the contact ratio of involute noncircular gear transmission are center distance $E$, transmission ratio coefficient $k_{1}$ and $b_{1}$, addendum coefficient $h_{a}{ }^{*}$, modification coefficient $x$, module $m$, and tooth profile angle of the rack cutter $\alpha_{0}$. Considering that the center distance $E$ and the expected transmission ratio function $m_{21}$ are unchanged, and the pitch curve of modified gear pair should be same as that of the original gear pair. To satisfy the above-mentioned conditions, when one noncircular gear with positive addendum modification is designed, the other one must be processed by negative addendum modification. Furthermore, the absolute value of the modification coefficient of the two gears should be equal. So only the height modification method with the modification coefficient $x_{2}=-x_{1}$ and total modification coefficient $\Sigma x=x_{1}+x_{2}=0$ can be used (Wu $\&$ Wang, 1997). As shown in Figure.6, zero modification has little effect on the contact ratio of noncircular gear.

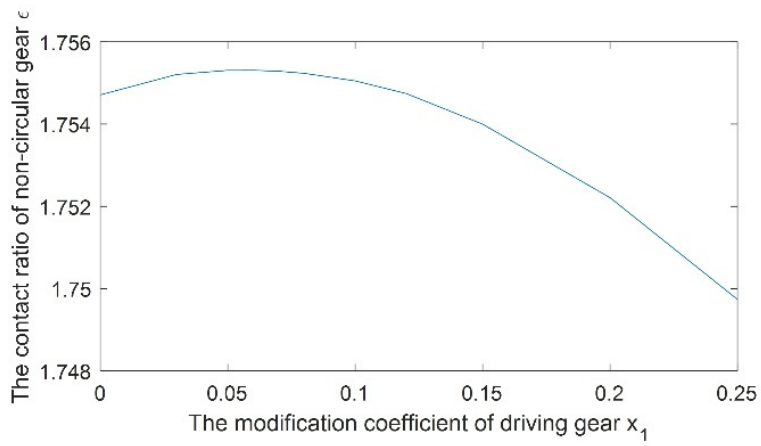

Figure 6 The influence of zero modification on the contact ratio of noncircular gear

Therefore, for a noncircular gear pair with determined pitch curve, the parameters affected the contact ratio are as following: tooth profile angle of rack cutter $\alpha_{0}$, modification coefficient $h_{a}^{*}$ and module $m$. When parameters of noncircular gear pair are selected as: $k_{1}=3 / 4 \pi, b_{1}=1.75, E=180 \mathrm{~mm}$, the influence of other parameters on the contact ratio of linear functional 
noncircular gear pair is shown in Figure.7.

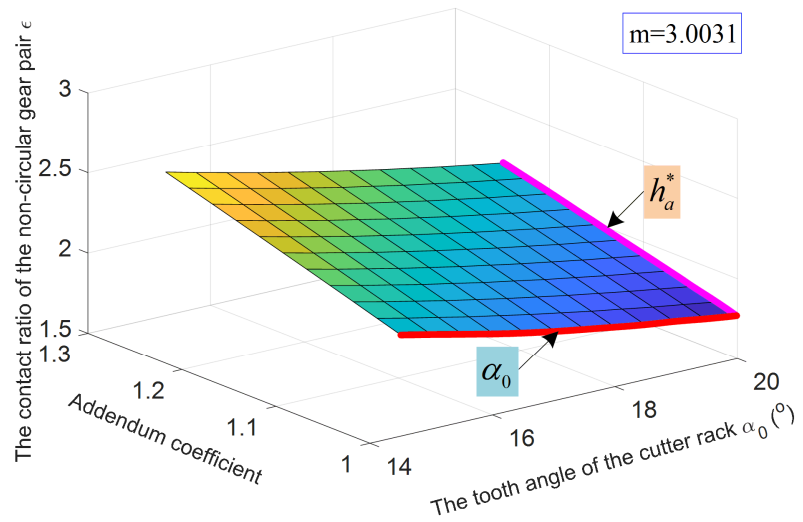

(a) The influence of the modification coefficient and tooth profile angle of the rack cutter on the contact ratio

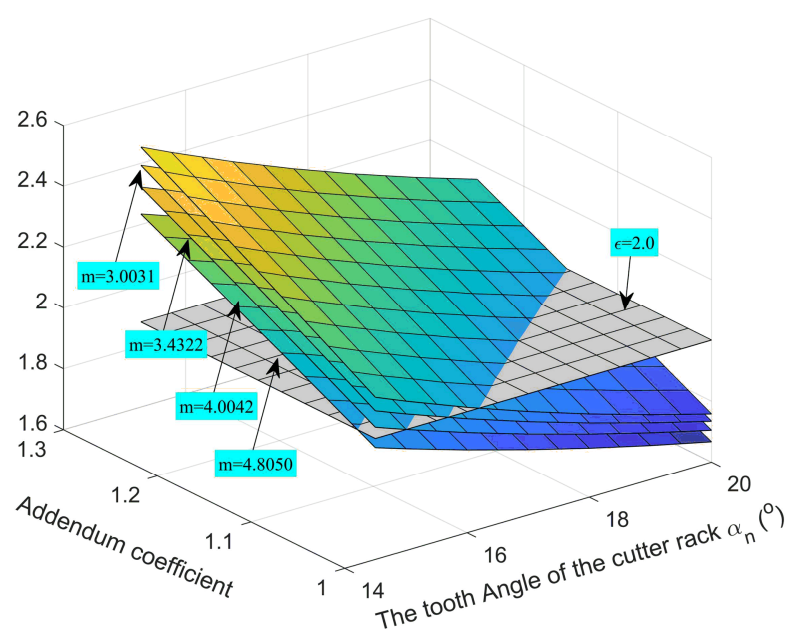

(b) The influence of module on the contact ratio

Figure 7 The influence of each parameter on the contact ratio

As shown in Figure.7, for a certain noncircular pitch curve, with the increase of the addendum coefficient $h_{a}{ }^{*}$ or the number of teeth $z$, the decrease of tooth profile angle $\alpha_{0}$ of the rack cutter or the modulus $m$, the minimum contact ratio of the noncircular gear pair in the working section will increase. In this paper, it is defined as high contact ratio while the minimum instantaneous contact ratio greater than 2. When parameters are taken as the surface above the plane $\varepsilon=2.0$ shown in Figure.10b, high contact ratio can be achieved. With respect to different linear functional pitch curves, the influence of transmission ratio coefficient on contact ratio is shown in Figure.8.

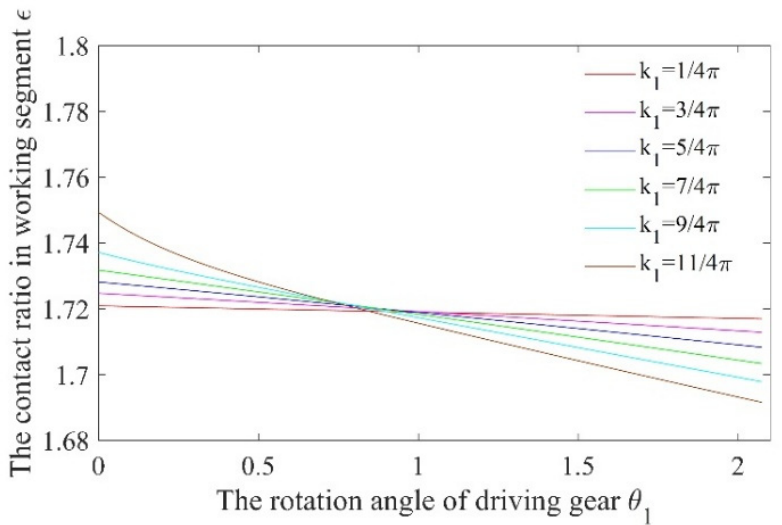

Figure 8 The influence of transmission ratio coefficient on contact ratio

It is obvious that the curvature variations in the working section increase with the transmission ratio coefficient $k_{1}$ increasing, and the smaller minimum contact ratio is also acquired.

\section{Involute Profile of Noncircular Gear}

Based on the pitch curve of noncircular gear, the involute tooth profile of noncircular gear can be obtained. The design of noncircular gear tooth profile is to determine its geometric parameters and make it have reasonable meshing performance. For example, the tooth profile of noncircular gear is required to ensure that the two calculated curves are pure rolling (i.e. transmission according to the required transmission ratio) and have appropriate pressure angle. As we all know, the noncircular gear pair has directionality when it is meshed correctly. When the driving gear rotates clockwise, the transmission ratio of the gear pair is a required linear function. At this time, both the driving gear and the driven gear are meshed with the right tooth profile. Therefore, this paper takes the right tooth profile of the driving gear as the research object, and for simplicity, the following tooth profiles without special description are called the right tooth profile of driving gear.

\subsection{Involute Profile of Driving Gear}

In noncircular gear pair transmission, coordinate system $S_{1}\left(O_{1}-x_{1} y_{1} z_{1}\right)$ is rigidly connected to driving gear, and its initial position is shown in the Figure.9. In the initial position, polar axis of driving gear coincides with $y$-axis of the fixed coordinate frame $S_{0}(O-x y z)$, and the $x_{1}$-axis of coordinate system $S_{1}$ is parallel to the $\mathrm{x}$-axis of the fixed coordinate frame with a spacing of $r_{1}(0)$. To simplify calculation, the right profile of the $1 \#$ tooth passes through the instantaneous center $O$ at the initial position, and $O$ must be a point on 
the meshing curve.

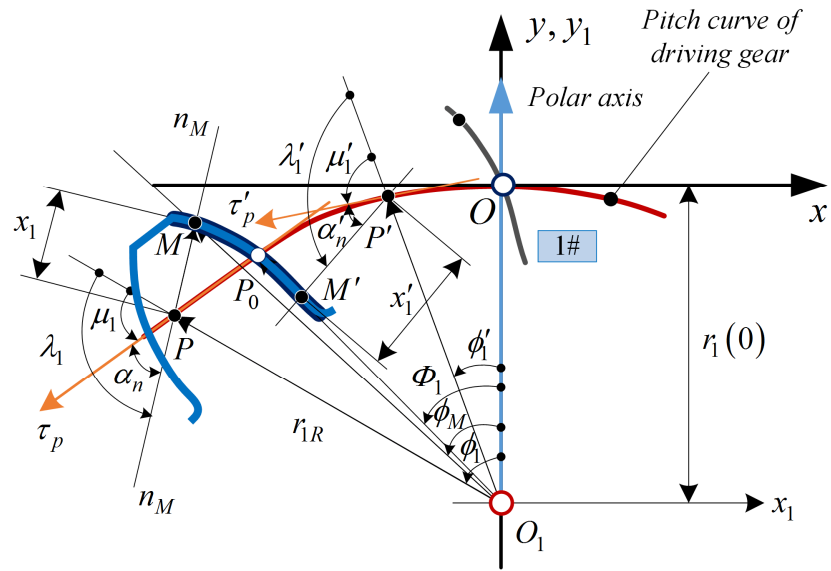

Figure 9 The analytical diagram of tooth profile of driving gear

As shown in Figure.9, one right tooth profile on the driving gear intersects with pitch curve at point $P_{0} . M$ is the point on this tooth profile above the pitch curve, and $M^{\prime}$ is the point on this tooth profile below the pitch curve. Taking the point $M$ for example, the normal $n_{M} n_{M}$ of point $M$ intersects the pitch curve at point $P$, which is the instantaneous center of the gear pair when point $M$ is the meshing point, and the tangent of point $P$ on the pitch curve is named $\tau_{P} \tau_{P}$. In the coordinate system $S_{1}$, the equation of the tooth profile $\vec{r}_{1 R}$ is

$$
\overrightarrow{r_{1 R}}=\overrightarrow{O_{1} M}=\overrightarrow{O_{1} P}+\overrightarrow{P M}
$$

Where, $\overrightarrow{O_{1} P}=r_{1}\left(\phi_{1}\right)$, and in terms of involute property,

$$
x_{1}=|\overrightarrow{P M}|=\overparen{P P_{0}} \cos \alpha_{n}=\cos \alpha_{n} \cdot \int_{\Phi_{1}}^{\phi_{1}} \sqrt{r_{1}^{\prime 2}(\phi)+r_{1}^{2}(\phi)} d \phi
$$

It is noteworthy that $x_{1}^{\prime}=\left|\overrightarrow{P^{\prime} M^{\prime}}\right|=\overparen{P^{\prime} P_{0}} \cos \alpha_{n}=\cos \alpha_{n}$. $\int_{\phi_{1}^{\prime}}^{\Phi_{1}} \sqrt{r_{1}^{\prime 2}(\phi)+r_{1}^{2}(\phi)} d \phi$ while the point $M^{\prime}$ on this tooth profile is below the pitch curve owing to $\phi_{1}^{\prime}<\Phi_{1}$.

In addition, at the meshing point $P$, the angle $\lambda_{1}$ between the radial vector $\overrightarrow{O_{1} P}\left(=r_{1}\left(\phi_{1}\right)\right)$ of the pitch curve and the normal $n_{M} n_{M}$ of the right tooth profile is

$$
\lambda_{1}=\alpha_{n}+\mu_{1}
$$

where, $\mu_{1}$ is the angle between the radial vector $\vec{r}_{1}\left(\phi_{1}\right)$ of the pitch curve and the positive direction of tangent vector $\vec{\tau}_{p}$ at point $P$, and the measuring direction of angle $\lambda_{1}$ is the same as that of angle $\mu_{1}$; and the angle $\alpha_{n}$ represents the tooth profile angle of cutter.
Further, the radial vector of the tooth profile $\vec{r}_{1 R}$ in the coordinate system $S_{1}$ can be obtained as

$$
\begin{aligned}
{\overrightarrow{r_{1 R}}}^{(1)} & =\left[\begin{array}{l}
x_{1 R} \\
y_{1 R}
\end{array}\right]=\left[\begin{array}{l}
\left|\overrightarrow{r_{1 R}}\right| \sin \phi_{M} \\
\left|\overrightarrow{r_{1 R}}\right| \cos \phi_{M}
\end{array}\right] \\
& =\left[\begin{array}{l}
-r_{1}\left(\phi_{1}\right) \sin \phi_{1} \pm x_{1} \sin \left(\phi_{1}+\lambda_{1}\right) \\
r_{1}\left(\phi_{1}\right) \cos \phi_{1} \mp x_{1} \cos \left(\phi_{1}+\lambda_{1}\right)
\end{array}\right]
\end{aligned}
$$

Where, the above symbol is used for the point above the pitch curve; and the below symbol is used for the point below the pitch curve.

And the polar coordinate equation of the right tooth profile of the driving gear is as follows:

1) While the point $M$ on the tooth profile is above the pitch curve

$$
\left\{\begin{array}{l}
r_{1 R}\left(\phi_{1}\right)=\sqrt{r_{1}^{2}\left(\phi_{1}\right)+x_{1}^{2}+2 r_{1}\left(\phi_{1}\right) x_{1} \cos \lambda_{1}} \\
\phi_{M}\left(\phi_{1}\right)=\arctan \frac{-r_{1}\left(\phi_{1}\right) \sin \phi_{1}+x_{1} \sin \left(\phi_{1}+\lambda_{1}\right)}{r_{1}\left(\phi_{1}\right) \cos \phi_{1}-x_{1} \cos \left(\phi_{1}+\lambda_{1}\right)}
\end{array}\right.
$$

2) While the point $M^{\prime}$ on the tooth profile is below the pitch curve

$$
\left\{\begin{array}{l}
r_{1 R}\left(\phi_{1}\right)=\sqrt{r_{1}^{2}\left(\phi_{1}\right)+x_{1}^{2}-2 r_{1}\left(\phi_{1}\right) x_{1} \cos \lambda_{1}} \\
\phi_{M}\left(\phi_{1}\right)=\arctan \frac{-r_{1}\left(\phi_{1}\right) \sin \phi_{1}-x_{1} \sin \left(\phi_{1}+\lambda_{1}\right)}{r_{1}\left(\phi_{1}\right) \cos \phi_{1}+x_{1} \cos \left(\phi_{1}+\lambda_{1}\right)}
\end{array}\right.
$$

In the same way, the polar coordinate equation of the right tooth profile of the driven gear also can be obtained

1) While the point $M$ on the tooth profile is above the pitch curve

$$
\left\{\begin{array}{l}
r_{2 R}\left(\phi_{1}\right)=\sqrt{r_{2}^{2}\left(\phi_{1}\right)+x_{2}^{2}+2 r_{2}\left(\phi_{1}\right) x_{2} \cos \lambda_{2}} \\
\phi_{2 M}\left(\phi_{1}\right)=\arctan \frac{-r_{1}\left(\phi_{1}\right) \sin \phi_{2}-x_{2} \sin \left(\phi_{2}+\lambda_{2}\right)}{r_{2}\left(\phi_{1}\right) \cos \phi_{2}+x_{2} \cos \left(\phi_{2}+\lambda_{2}\right)}
\end{array}\right.
$$

2) While the point $M^{\prime}$ on the tooth profile is below the pitch curve

$$
\left\{\begin{array}{l}
r_{2 R}\left(\phi_{1}\right)=\sqrt{r_{2}^{2}\left(\phi_{1}\right)+x_{2}^{2}-2 r_{2}\left(\phi_{1}\right) x_{2} \cos \lambda_{2}} \\
\phi_{2 M}\left(\phi_{1}\right)=\arctan \frac{-r_{1}\left(\phi_{1}\right) \sin \phi_{2}+x_{2} \sin \left(\phi_{2}+\lambda_{2}\right)}{r_{2}\left(\phi_{1}\right) \cos \phi_{2}-x_{2} \cos \left(\phi_{2}+\lambda_{2}\right)}
\end{array}\right.
$$

\subsection{The Meshing Curve of Noncircular Gear Pair}

As is known, each pair of conjugate tooth profile of 
noncircular gear pair is generally different, so its meshing curve is also different $(\mathrm{Li}, 1983)$.

As shown in the Figure.10, at the initial position, of noncircular gear pair transmission, one point $M^{\prime}$ on the right tooth profile of driving gear whose polar coordinates is $\left(\phi_{M}, r_{1 R}\right)$, and the normal of the right tooth profile and pitch curve intersect at $P^{\prime}$. When the driving wheel has rotated angle of $\theta_{1}$ clockwise, which $\theta_{1}$ are equal to $\phi_{1}$ with opposite direction, $P^{\prime}$ turned to $P, M^{\prime}$ turned to $M$, and the radial vector of pitch curve coincides with $y$-axis of fixed coordinate frame $S_{0}$ at this moment. According to the principle of gearing, when the point $P$ falls on the line between the centers of the two gears, the point $M$ on the tooth profile of the driving gear is tangent to the corresponding point on its conjugate tooth profile, and the point $M$ is one point on the meshing curve of this noncircular gear pair.

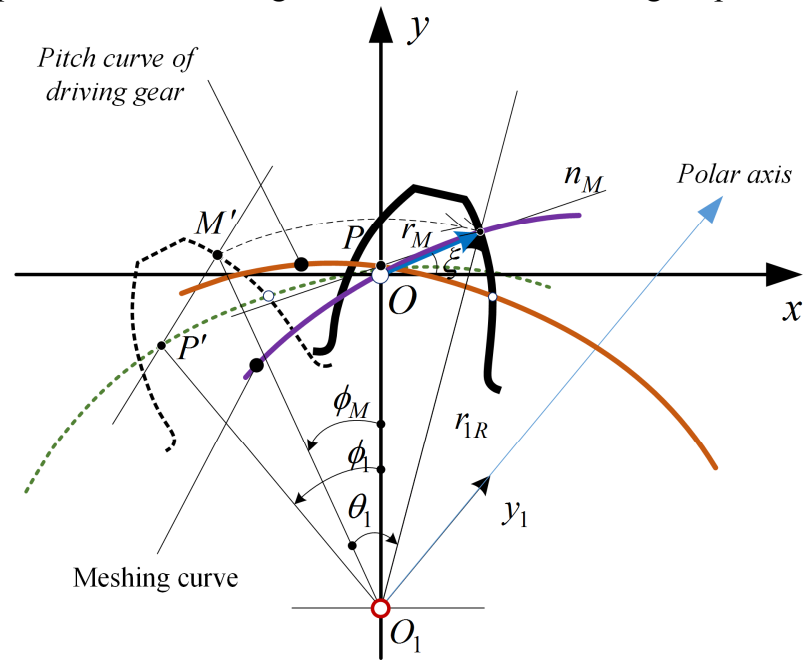

Figure 10 The analytical diagram of meshing curve of noncircular gear pair

The rotating angle of driving gear $\theta_{1}$ is the angle between reference frame $S_{0}$ and $S_{1}$. The coordinate transformation matrix from $S_{1}$ to $S_{0}$ is as follows:

$$
M_{01}=\left[\begin{array}{ccc}
\cos \theta_{1} & \sin \theta_{1} & 0 \\
-\sin \theta_{1} & \cos \theta_{1} & r_{1}(0) \\
0 & 0 & 1
\end{array}\right]
$$

By transforming the radial vector of the tooth profile $\vec{r}_{1 R}$ into the fixed coordinate frame $S_{0}$, the meshing curve of gear pair can be obtained

$$
\overrightarrow{r_{M}}=M_{01} \overrightarrow{r_{1 R}} \overrightarrow{(1)}^{(1)}=\left[\begin{array}{ccc}
\cos \theta_{1} & \sin \theta_{1} & 0 \\
-\sin \theta_{1} & \cos \theta_{1} & r_{1}(0) \\
0 & 0 & 1
\end{array}\right]\left[\begin{array}{c}
x_{1 R} \\
y_{1 R} \\
1
\end{array}\right]
$$

By the way, $\theta_{1}$ are equal to $\phi_{1}$, and the meshing curve of noncircular gear pair in fixed coordinate frame $S_{0}$ can be expressed as

$$
\left\{\begin{array}{l}
x_{M}=x_{1 R} \cos \phi_{1}+y_{1 R} \sin \phi_{1} \\
y_{M}=-x_{1 R} \sin \phi_{1}+y_{1 R} \cos \phi_{1}+r_{1}(0)
\end{array}\right.
$$

As shown in Figure.11, the theoretical results of some meshing curves have been obtained by MATLAB. The azure curve in Figure.11 is the meshing curve of $1 \#$ tooth, and above are the meshing curves from $2 \#$ tooth to $18 \#$ tooth, where, the teeth from $2 \#$ to $16 \#$ are fully on the working section, the upper half of $1 \#$ tooth profile and lower half of $17 \#$ tooth profile are in the working section, and the $18 \#$ tooth is completely on the non-working section as the red curve in Figure.11.

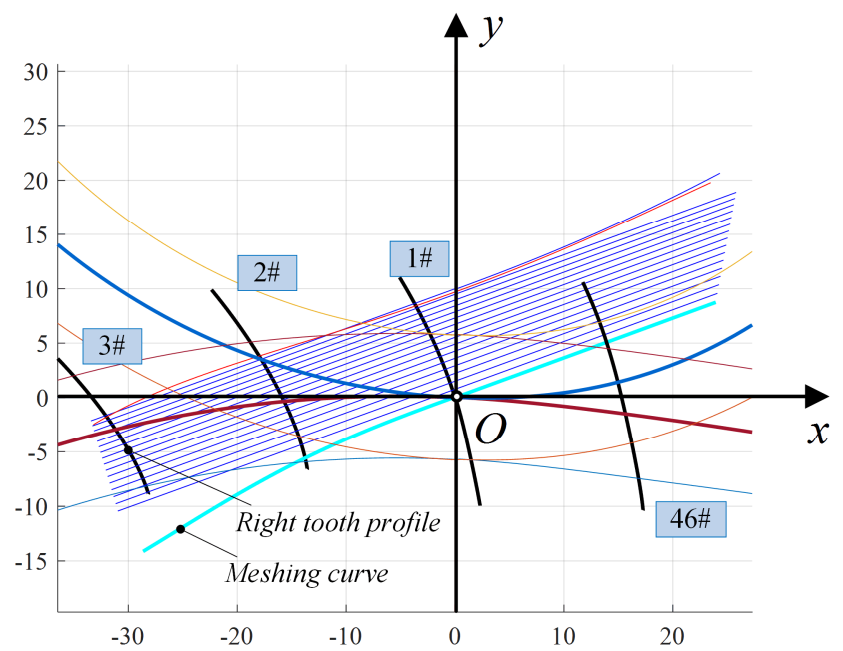

Figure 11 The theoretical results of some meshing curves of noncircular gear pair by MATLAB

\subsection{The Length of Contact Profile of Driving Gear}

The meshing process of a pair of conjugate tooth profiles is from addendum of driven gear peak contacting to addendum of driving gear peak contacting. Therefore, in the fixed coordinate frame $S_{0}$, the intersection point $F$ of the meshing curve and the addendum curve of the driven gear is the starting point of the contact profile of the driving gear, and the intersection point $A$ of the addendum curve and the tooth profile of the driving gear is the end point of the contact profile of the driving gear. $2 \#$ tooth is taken as an example as shown in Figure.12. 


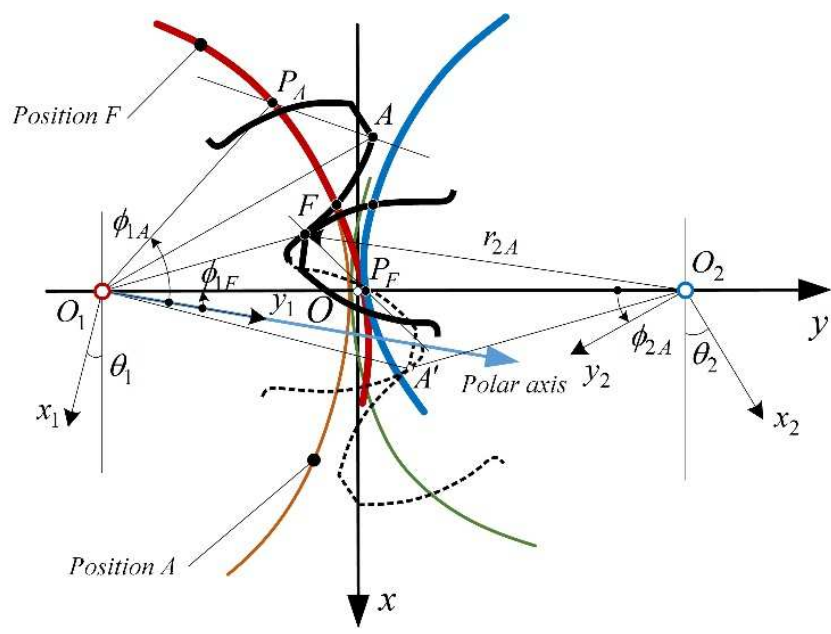

Figure 12 The analytical diagram of contact profile of driving gear and the addendum curve of driven gear

The addendum curve (Wu \& Wang, 1997) of driven gear in the reference system $S_{2}\left(O_{2}-x_{2} y_{2} z_{2}\right)$, which is rigidly attached to driven gear, can be presented as

$$
\left\{\begin{array}{l}
r_{2 A}\left(\varphi_{2}\right)=\overline{O_{2} A_{2}}=\sqrt{r_{2}^{2}\left(\varphi_{2}\right)+h_{a}^{2}+2 r_{2}\left(\varphi_{2}\right) h_{a} \sin \mu_{2}} \\
\varphi_{2 A}\left(\varphi_{2}\right)=\varphi_{2}-\arcsin \frac{h_{a} \cos \mu_{2}}{r_{2 A}\left(\varphi_{2}\right)}
\end{array}\right.
$$

The following simultaneous equations can be used to get the intersection point of the tooth profile as (16) and the addendum curve as (21) of the driven gear.

$$
\left\{\begin{array}{l}
r_{2 R}\left(\phi_{1}\right)=r_{2 A}\left(\varphi_{2}\right) \\
\phi_{2 M}\left(\phi_{1}\right)=\varphi_{2 A}\left(\varphi_{2}\right)
\end{array}\right.
$$

And a unique solution $\left(\phi_{1}, \varphi_{2}\right)$ can be obtained from the above equations. Substituting the solution into the tooth profile equation of the driven gear, the tooth addendum point $F\left(\phi_{2 F}\left(\phi_{1}\right), r_{2 F}\left(\phi_{1}\right)\right)$ of the driven gear can be obtained. According to the principle of gears, the solution of $\phi_{1}$ is the pitch curve angle $\phi_{1 F}$ when the tooth of driving gear enter into meshing.

Similarly, the tooth addendum point $A\left(\phi_{1 A}\left(\phi_{1}\right), r_{1 A}\left(\phi_{1}\right)\right)$ of the driving gear also can be obtained, and at this time, the value of $\phi_{1}$ is the pitch curve angle $\phi_{1 A}$ when the tooth of driving gear is out of meshing. The theoretical length of contact profile of the tooth $l_{1}$ is obtained as follows,

$$
l_{1}=\int_{\phi_{1 F}}^{\phi_{1 A}} \sqrt{x_{1 R}^{\prime 2}+y_{1 R}^{\prime 2}} d \phi_{1}
$$

As shown in Figure.13, the 2\# theoretical contact tooth profile $\overparen{P_{1} P_{2}}$ of driving gear has been obtained by MATLAB. In addition, according to the results of contact stress by ANSYS, there are double tooth-meshing area and three tooth-meshing area on the actual meshing curve $\overparen{P_{1} P_{2}^{\prime}}$.

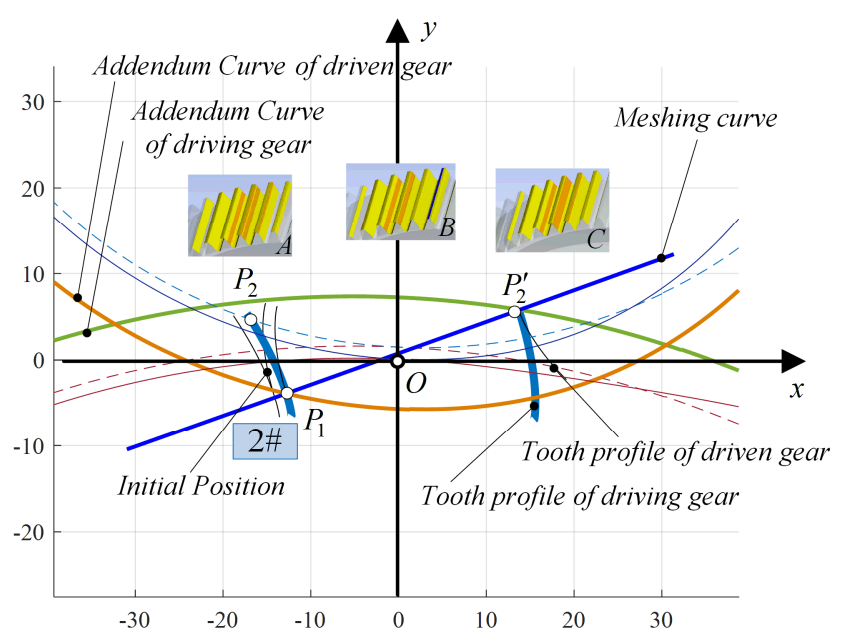

Figure 13 The 2\# theoretical contact tooth profile of driving gear by MATLAB

\section{Experimental Verification}

Combined with the above analysis, in order to achieve high contact ratio transmission, the noncircular gear pair parameters are selected as shown in the Table 1.

Table 1 Parameter values of noncircular gear pair

\begin{tabular}{ll}
\hline \hline Parameter & Value \\
\hline$k_{1}$ & $3 / 4 \pi$ \\
$b_{1}$ & 1.75 \\
$E$ & $172.32 \mathrm{~mm}$ \\
$m$ & 5 \\
$z_{1}$ & 46 \\
$z_{2}$ & 23 \\
$\alpha$ & $18^{\circ}$ \\
$h_{a}^{*}$ & 1.15 \\
\hline \hline
\end{tabular}

The tooth profile curve of noncircular gear pair obtained by simulating the machining process of slotting cutter with MATLAB are shown in Figure.14. The tooth profile points of noncircular gear pair obtained by MATLAB are imported into SolidWorks to establish the model, and the final model of noncircular gear pair used for machining is obtained after smoothing the tooth surface. 


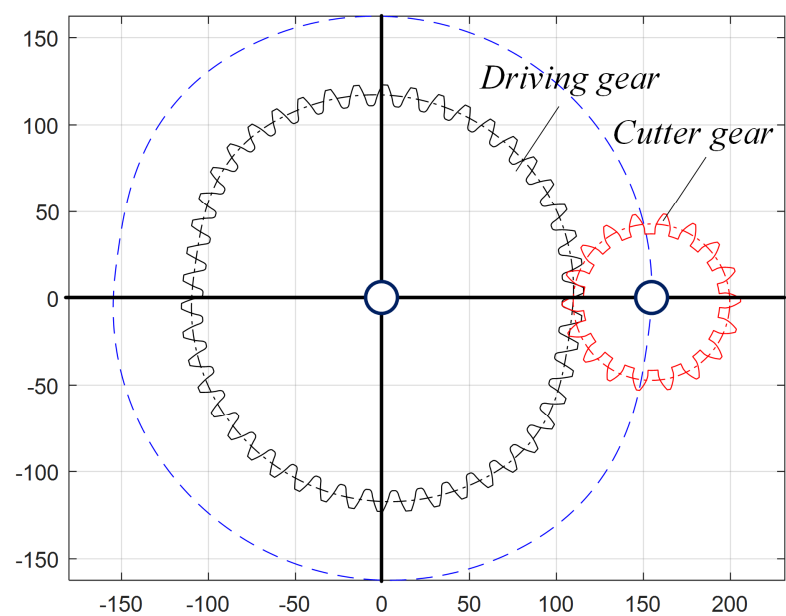

(a) Tooth profile curve of driving gear

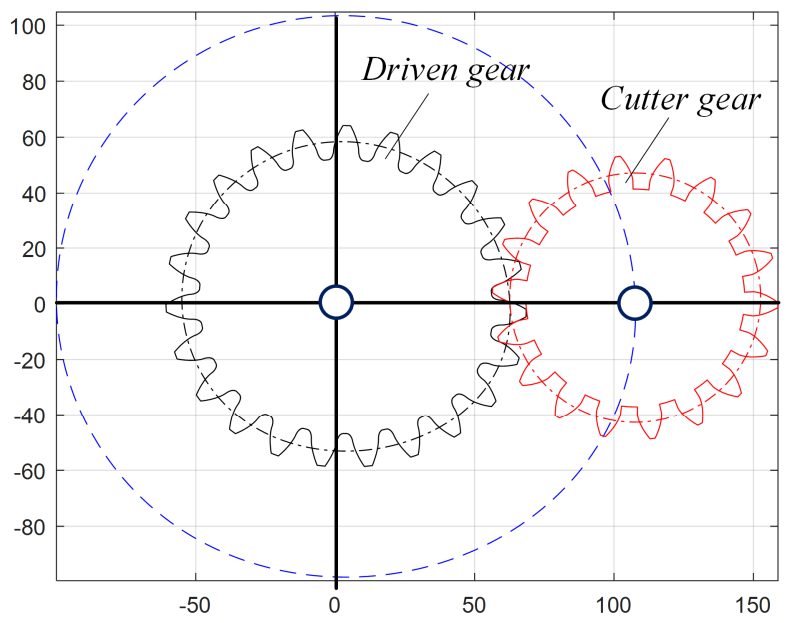

(b) Tooth profile curve of driven gear

Figure 14 The tooth profile curve of noncircular gear pair with MATLAB

In order to measure of the transmission ratio and the contact length of tooth profile of noncircular gear pair, after finishing the processing of the noncircular gear pair through the five-axis CNC machining center, the noncircular gear rolling test is carried on the comprehensive experimental test platform of the noncircular gear transmission, and the experimental test platform is shown in Figure.15.

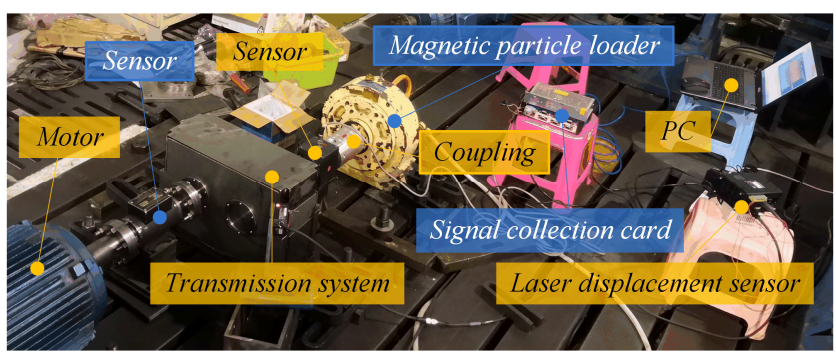

Figure 15 The experimental test platform of the noncircular gear transmission

The drive motor provides input torque and speed, and drives the driving gear to rotate, then the driven gear drives the magnetic particle loader to rotate. The input torque tachometer installed between drive motor and gear case can measure the input torque, rotational velocity and other parameters. The output torque tachometer installed between the magnetic particle loader and gear case can measure the output torque, rotational velocity and other parameters. The input / output torque and rotational velocity are fed back to the operation console for post processing. And these parameters including load torque and speed of the drive motor can be further adjusted by operation console.

To minimize the influence of error caused by random signal interference on experimental results, the acquired experimental data must be processed. Therefore, the actual transmission ratio $i_{12}^{\prime}$ is obtained from (24).

$$
i_{12}^{\prime}=\frac{\omega_{1}{ }^{\prime}}{\omega_{2}{ }^{\prime}}=\frac{n_{1}{ }^{\prime}}{n_{2}{ }^{\prime}}
$$

Where, $\omega_{1}{ }^{\prime}$ and $n_{1}{ }^{\prime}$ are angular velocity and rotating speed of driving gear, respectively. $\omega_{2}{ }^{\prime}$ and $n_{2}{ }^{\prime}$ are angular velocity and rotating speed of driven gear, respectively.

Due to the involute profile of noncircular gear, the contact ratio error can be reflected by the contact profile length error. As is known, the actual meshing curve of noncircular gear pair is very important for reflecting the contact ratio of this gear pair. According to the actual meshing curve of gear pair, the tooth profile that actually participates in meshing can be known, that is, the working section of tooth profile. Therefore, it is proposed to check the error of contact ratio indirectly by measuring the error of the working section of tooth profile. The surface of the whole tooth or only the tooth addendum of the driven gear is coated with a uniform layer of red lead powder, which is shown in Fig16 a).

After noncircular gear pair turning a cycle, the contact marks with red lead powder are left on the teeth surface of the driving gear, that is, the initial position of contact tooth profile, which is shown in Figure.16 b). Then the contact mark on the driving gear surface is recorded by A4 paper and scanned into computer, and the error of the contact tooth profile length is obtained through data processing. 1\# and 3\# teeth of noncircular gear pair are taken as examples, and the contact area are shown in Figure.16 c), where $l_{2}$ is the length of experimental contact tooth profile, and $l_{0}$ is the length of tooth profile. 


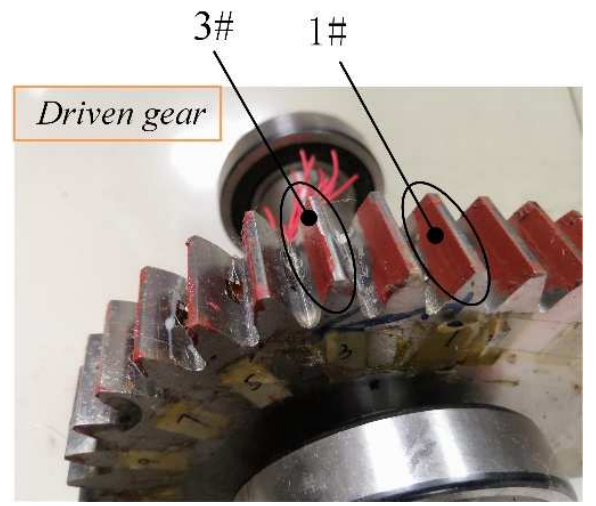

(a) The driven noncircular gear

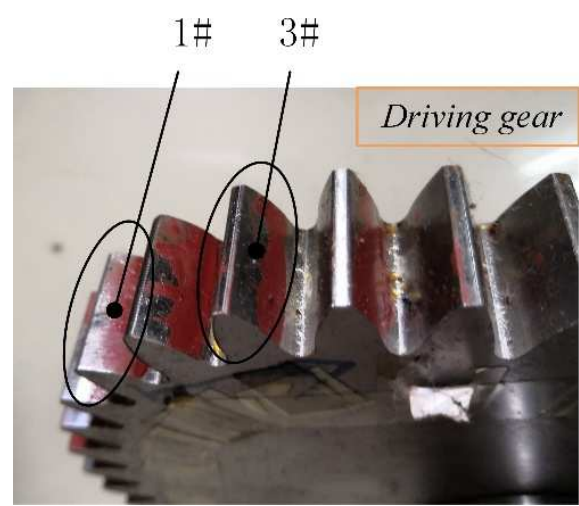

(b) The driving noncircular gear

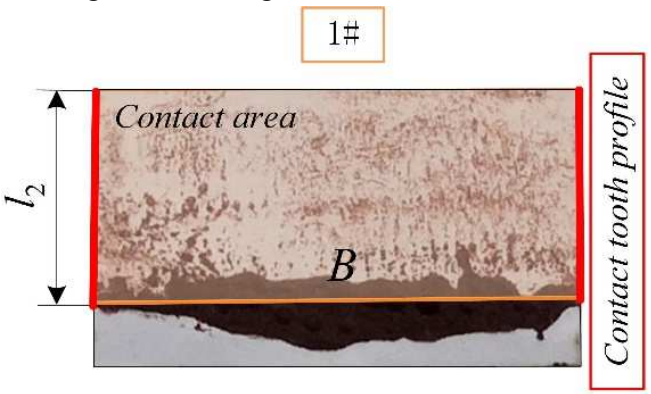

(c) The contact area of $1 \#$ teeth of driving gear

$3 \#$

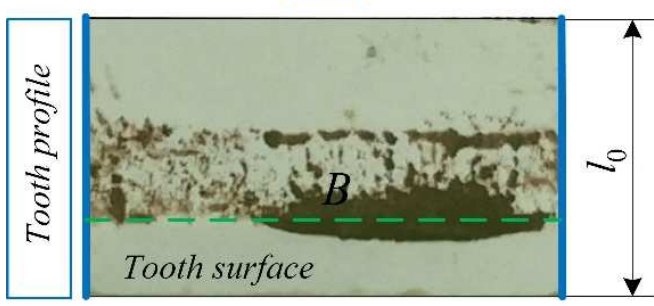

(d) The tooth surface of $3 \#$ teeth of driving gear

Figure 16 The length of contact profile of driving gear

The length error of contact tooth profile $e_{\varepsilon}$ is obtained by analyzing the length of experimental contact profile $l_{2}$ and theoretical contact profile $l_{1}$ according to (25).

$$
e_{\varepsilon}=\frac{|\Delta l|}{l_{1}} \times 100 \%=\frac{\left|l_{1}-l_{2}\right|}{l_{1}} \times 100 \%
$$

Figure.17 shows the comparisons between the theoretical and experimental results of transmission ratio and contact tooth profile length of the noncircular gear pair.

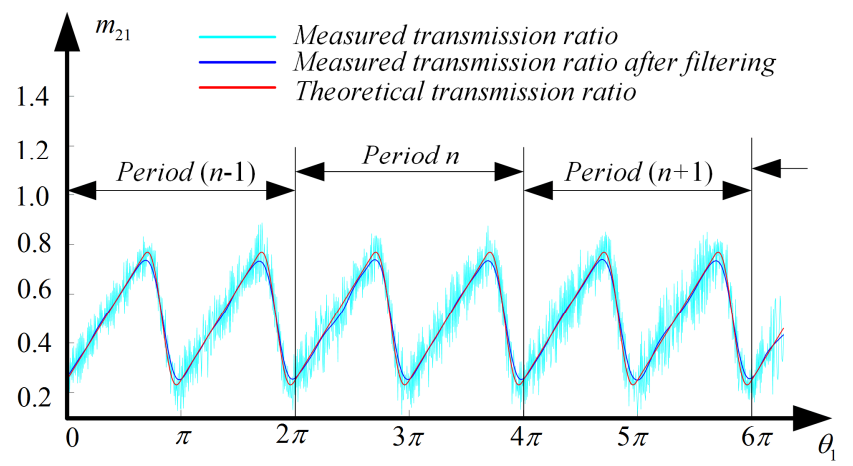

(a) The transmission ratio

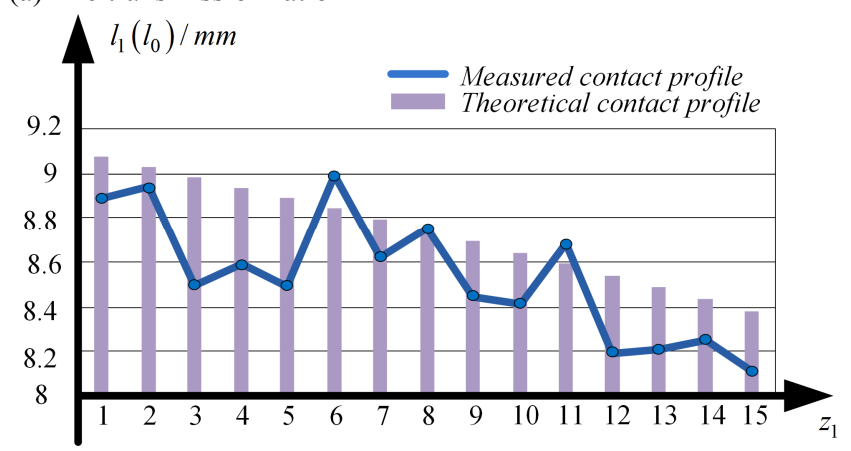

(b) The contact profile length of driven gear

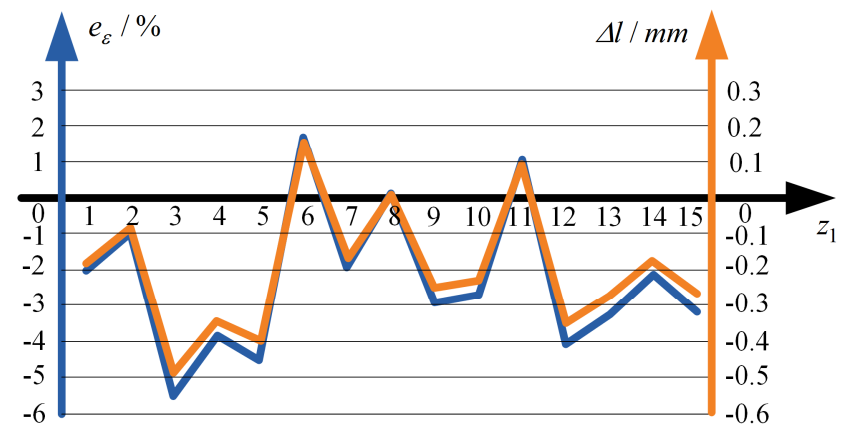

(c) The length error of contact tooth profile

Figure 17 The transmission ratio and contact profile length of the driving gear

Those results in Figure. 17 show that: 1) Except the errors caused by measurement and installation, the experimental value of the transmission ratio of the noncircular gear pair is basically consistent with the sliding blocks of the theoretical value, and the period of the experimental value is consistent with the period of the theoretical value. Because the experiment is carried out under the condition of low speed 
and light load, the influence caused by the dynamic characteristics of the noncircular gear can be ignored, and the error between the experimental results and the theoretical results is relatively small. In the working section, the maximum error of the transmission ratio is $6.18 \%$, the maximum error of the non-working section is $5.19 \%$, and the maximum error mainly lies in the connection between the working section and the non-working section. 2) It can be seen from the comparison results of the contact tooth profiles of noncircular gears that in a meshing period, the experimental values of the contact tooth profiles of noncircular gear are basically consistent with the sliding blocks of the theoretical values, and the experimental values are consistent with the theoretical values, which verifies the feasibility of the theoretical analysis method. The fluctuation amplitude of the experimental contact tooth profiles is greater than the theoretical results, and the experimental contact tooth profiles are lower than the theoretical values, and the maximum error of the working section is $5.4 \%$. The main reason for this result is that in order to ensure the noncircular gear pair normal meshing, the backlash is ensured by slightly increasing the installment center distance, which makes the actual contact profile smaller. In addition, the gear machining accuracy is also an important factor leading to the actual contact profile length decreasing.

\section{Conclusions}

In this paper, the linear functional noncircular gear pair is used to realize continuously variable transmission by means of branch-differential coupling, and the pitch curve of the linear functional noncircular gear pair is designed; The influence of the parameters of linear function, $k_{1}$ and $b_{1}$, on the pitch curve of the noncircular gear pair with linear functional transmission ratio in non-working section is analyzed, and the most suitable pitch curve form is obtained, which each value of $k_{1}$ must correspond to the best value of $b_{1}$. When the pitch curve in non-working section constructed by six-order polynomial meets the optimal conditions, the non-working section of the pitch curve is the slowest and the best. When $k_{1}$ increases gradually, even if $b_{1}$ is the most suitable value to make the variation trend of the pitch curve in the non-working section is the most gentle. However, the minimum curvature radius of pitch curve of driving/ driven gear is too small, so that the strength of gear teeth is insufficient, and the instantaneous speed and acceleration are too large, resulting in unstable transmission. This method can be used to design the noncircular gear pair which is suitable for CVT. The experiment platform of noncircular gear pair transmission is built to verify the correctness of the design of noncircular gear pair transmission ratio. The comprehensive influence of each parameter on the contact ratio of the noncircular gear pair is analyzed. The larger the transmission ratio parameter $k_{1}$ of the linear functional noncircular gear pair is, the larger the variation range in the working section is, and the smaller the minimum contact ratio is. In terms of the principle of gear and the property of involute profile, the tooth profiles and meshing curves of noncircular gear are obtained, and then the length of every contact tooth profile is gotten. By measuring the length error of contact tooth profile, the error of contact ratio is detected indirectly, and the correctness of the design of high contact ratio of noncircular gear pair is verified.

\section{Declaration}

\section{Acknowledgements}

The authors sincerely thanks to Professor Jing Wei of Chongqing University for his critical discussion and reading during manuscript preparation.

\section{Funding}

Supported by National Natural Science Foundation of China (Grant No. 51675060), Equipment Pre-Research Project (Grant No. 3010519404), Chongqing University Graduate Student Research Innovation Project (Grant No. CYB19011), and National Natural Science Foundation of China (Grant No. U1864210).

\section{Availability of data and materials}

The datasets supporting the conclusions of this article are included within the article.

\section{Authors' contributions}

The author' contributions are as follows: Chao Lin and $\mathrm{Ya}-\mathrm{Nan} \mathrm{Hu}$ were in charge of the whole trial; Ya-Nan $\mathrm{Hu}$ and Chun-Jiang He wrote the manuscript; Yong-Quan Yu and Zhi-Qin Cai assisted with sampling and laboratory analyses.

\section{Competing interests}

The authors declare no competing financial interests.

\section{Consent for publication}

Not applicable

Ethics approval and consent to participate

Not applicable 


\section{References}

Addomine, M., Figliolini, G., \& Pennestrì, E. (2018). A landmark in the history of non-circular gears design: The mechanical masterpiece of Dondi's astrarium. Mechanism and Machine Theory, 122, 219232. https://doi.org/10.1016/j.mechmachtheory.2017.12.027

Alexandru, P., MacAveiu, D., \& Alexandru, C. (2012). A gear with translational wheel for a variable transmission ratio and applications to steering box. Mechanism and Machine Theory, 52, 267-276. https://doi.org/10.1016/j.mechmachtheory.2012.02.005

Chen, X., Hang, P., Wang, W., \& Li, Y. (2017). Design and analysis of a novel wheel type continuously variable transmission. Mechanism and Machine Theory, 107(4800), 13-26. https://doi.org/10.1016/j.mechmachtheory.2016.08.012

Dooner, D. B., Yoon, H.-D., \& Seireg, A. (1998). Kinematic considerations for reducing the circulating power effects in geartype continuously variable transmissions. Proceedings of the Institution of Mechanical Engineers, Part D: Journal of Automobile Engineering, 212(6), 463-478. https://doi.org/10.1243/0954407981526118

Emura, T., \& Arakawa, A. (1992). A new steering mechanism using noncircular gears. JSME INTERNATIONAL JOURNAL SERIES III-VIBRATION CONTROL ENGINEERING ENGINEERING FOR INDUSTRY, 35(4), 604-610. https://doi.org/10.1299/jsmec1988.35.604

Ferguson, R. J., Daws, L. F., \& Kerr, J. H. (1975). The design of a stepless transmission using non-circular gears. Mechanism and Machine Theory, 10(6), 467-478. https://doi.org/10.1016/0094$114 X(75) 90003-8$

Huang, Z., \& Lan, Z. (2011). Design of Transmission Ratio Function of Noncircular Gear of Closed Pitch Curve. Journal of Mechanical Transmission, 11, 34-37. https://doi.org/10.3969/j.issn.10042539.2011.11.008

Jian, L., \& Chau, K. T. (2010). Design and analysis of a magnetic-geared electronic-continuously variable transmission system using finite element method. Progress in Electromagnetics Research, 107(June), 47-61. https://doi.org/10.2528/PIER10062806

Li, F. (1983). Design of Noncircular Gear and Special Gear Transmission. China Machine Press.

Litvin, Faydor L, FuentesAznar, Alfonso, GonzalezPerez, Ignacio, \& Hayasaka, K. (2009). Noncircular Gears: Design and Generation. Cambridge University Press. https://doi.org/10.1017/CBO9780511605512

Litvin, F. L., \& Fuentes, A. (2004). Gear Geometry and Applied Theory. Cambridge University Press.

Litvin, F. L., Gonzalez-Perez, I., Fuentes, A., \& Hayasaka, K. (2008). Design and investigation of gear drives with non-circular gears applied for speed variation and generation of functions. Computer Methods in Applied Mechanics and Engineering, 197(45-48), 3783-3802. https://doi.org/10.1016/j.cma.2008.03.001

Machida, H., Itoh, H., Imanishi, T., \& Hirofumi, T. (1995). Design principle of high power traction drive CVT. International Congress \& Exposition, 1365-1375. https://doi.org/10.4271/950675

Ruan, Z. (1983). Mechanical continuously variable transmission. China
Machine Press.

Sun, G., Sun, C., Li, B., \& Zheng, F. (2015). Design Research of Noncircular Gears on Continuously Variable Transmission. Journal of Mechanical Transmission, 09, 62-65. https://doi.org/CNKI:SUN:JXCD.0.2015-09-015

Tang, J., Wang, Z., \& Lei, D. (2014). Study on the Relationship between Load and Gear Mesh Stiffness, Contact Ratio. Journal of Mechanical Transmission, 38(06), 1-4. https://doi.org/CNKI:SUN:JXCD.0.2014-06-002

Toru, F., Takemasa, K., \& Shigeru, K. (1993). A study of a metal pushing $V$-Belt type CVT-Part 1: relation between transmitted torque and pulley thrust. https://doi.org/10.4271/930666

Wu, X., \& Wang, G. (1997). Noncircular Gear and Non-uniform Velocity Ratio Transmission. China Machine Press.

Yildiz, A., Piccininni, A., Bottiglione, F., \& Carbone, G. (2016). Modeling chain continuously variable transmission for direct implementation in transmission control. Mechanism and Machine Theory, 105, 428-440. https://doi.org/10.1016/j.mechmachtheory.2016.07.015

Zheng, F., Hua, L., Han, X., Li, B., \& Chen, D. (2016). Synthesis of indexing mechanisms with non-circular gears. Mechanism and Machine Theory, 105, 108-128.

https://doi.org/10.1016/j.mechmachtheory.2016.06.019

Zheng, F., Xinghui, H., Hua, L., Zhang, M., \& zhang, W. (2018). Design and manufacture of new type of non-circular cylindrical gear generated by face-milling method. Mechanism and Machine Theory, 122, 326-346.

https://doi.org/10.1016/j.mechmachtheory.2018.01.007

\section{Biographical notes}

Ya-Nan Hu, born in 1993, is currently a PhD candidate in the State Key Laboratory of Mechanical Transmission, Chongqing University, China. From September, 2016 to now, she have been studying in Chongqing University for her master's and doctor's degree. Her research interests include theoretical research and application design of non-circular gear and curve-face gear composite transmission.

E-mail: 20160702030@cqu.edu.cn

Chao Lin, born in 1958, Ph.D., is a professor and doctoral supervisor of the College of Mechanical Engineering / the State Key Laboratory of Mechanical Transmission, Chongqing University, China. His research interests include meshing theory of spiral bevel gears, non-circular gears and new gear transmission, and precision transmission and drive.

Tel: +86-13452911958; E-mail: linchao@cqu.edu.cn

Chun-Jiang He, born in 1992, received the B.S. degree in mechanical engineering from Chongqing University, China, in 2011, and Ph.D. degree in mechanical engineering from Chongqing University, China, in 2020. Now, he is a Lecturer at the School of Mechanical and Power Engineering, Chongqing University of science and technology, University. His research interests include intelligent design and manufacturing.

E-mail: 20112407@cqu.edu.cn 
Yong-Quan Yu, born in 1994, received the B.S. degree in mechanical engineering from Hefei University of Technology, Hefei, in 2016. He is currently pursuing the Ph.D. degree in mechanical engineering at Chongqing University, Chongqing, China. His research interests include the development of the new type of gear transmission, fundamental study of curve-face gear, and surface topography of non-circular gear.

E-mail: 20160702017@cqu.edu.cn

Zhi-Qin Cai, born in 1988, is a lecturer at the School of Aeronautics and Astronautics, Xiamen University. He received his $\mathrm{PhD}$ in mechanical engineering from Chongqing University. His research interests include intelligent design of precision gear driven by shape coupling, micro-texture of tooth surface, and energy-saving transmission design.

E-mail: caizhiqin@xmu.edu.cn 
Figures

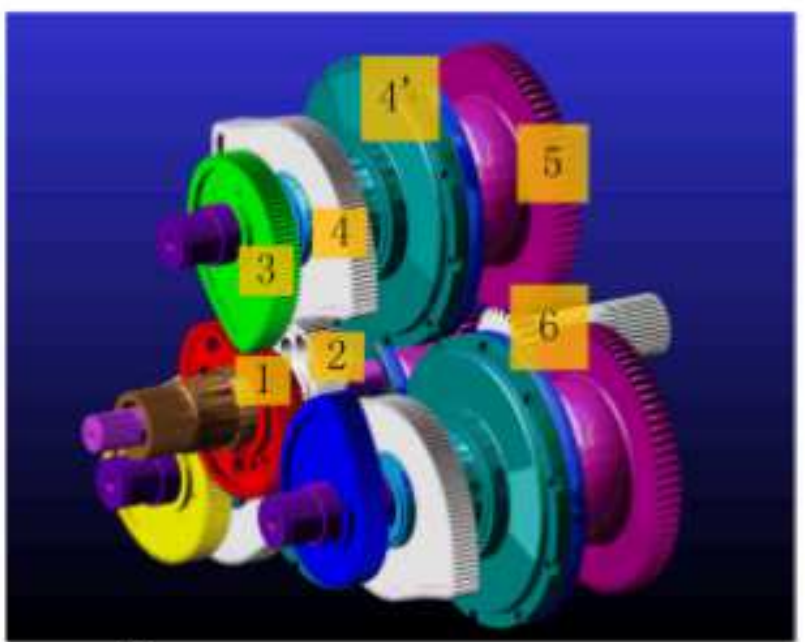

(a) System model

The double-row $2 \mathrm{~K}-\mathrm{H}$

epicyclic gear train

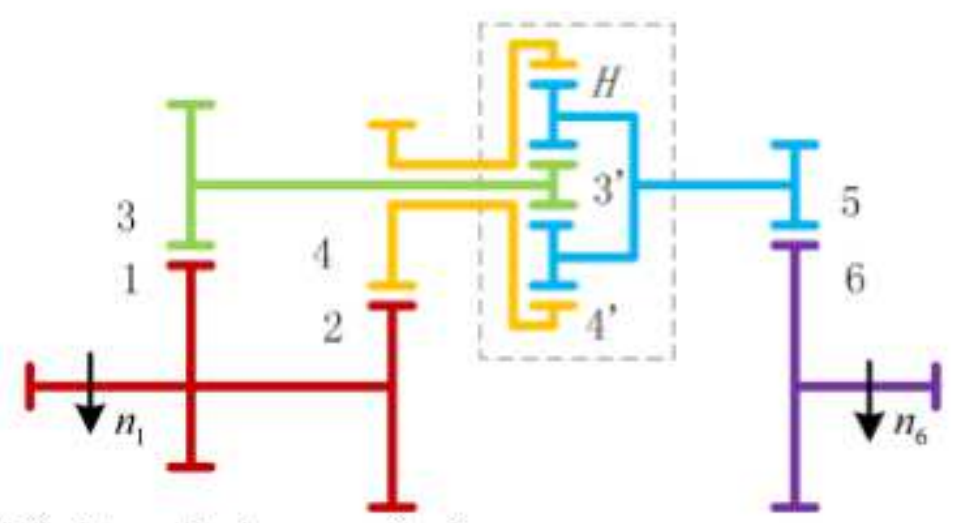

(b) Skeleton of scheme mechanism

Figure 1

Continuously variable noncircular gear transmission 


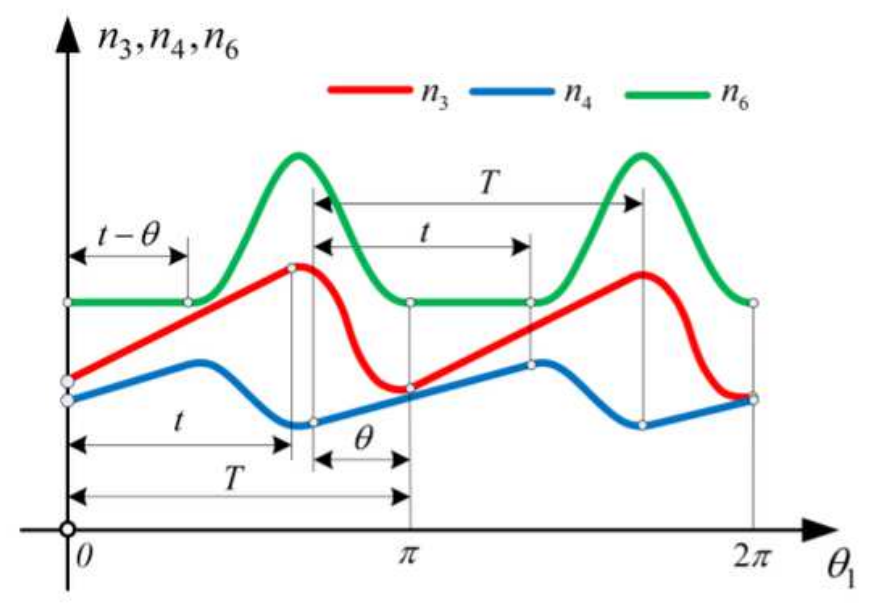

(a)

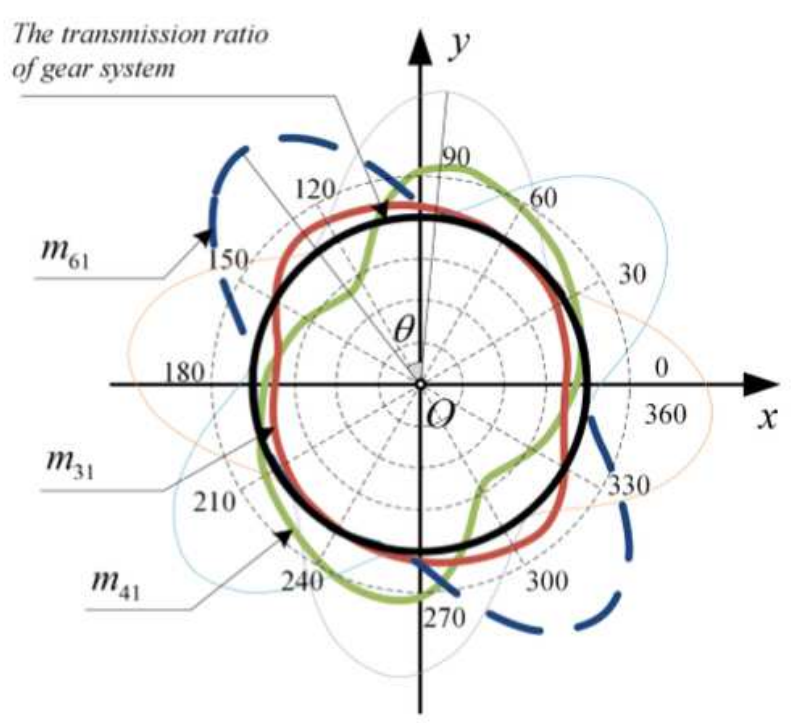

(b)

\section{Figure 2}

The basic transmission characteristics of continuously variable noncircular gear transmission a) Gear velocity at all levels in continuously variable noncircular gear transmission (b) The transmission ratio of each level in continuously variable noncircular gear transmission

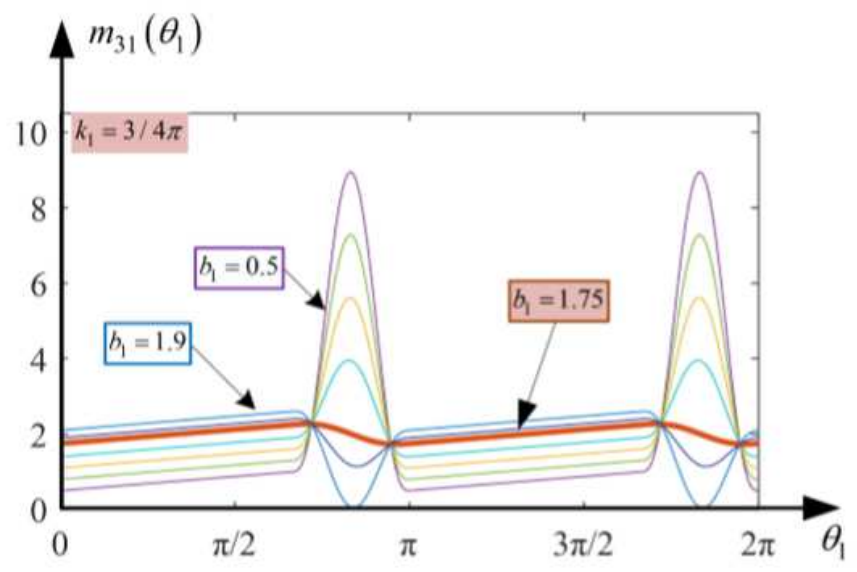

(a) The transmission ratio

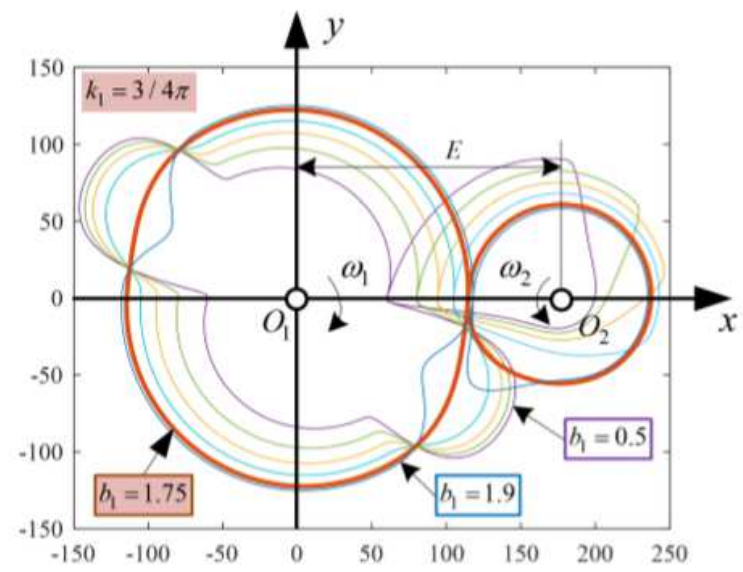

(b) The pitch curve

\section{Figure 3}

The influence of $1 \mathrm{~b}$ on transmission ratio of noncircular gear pair 


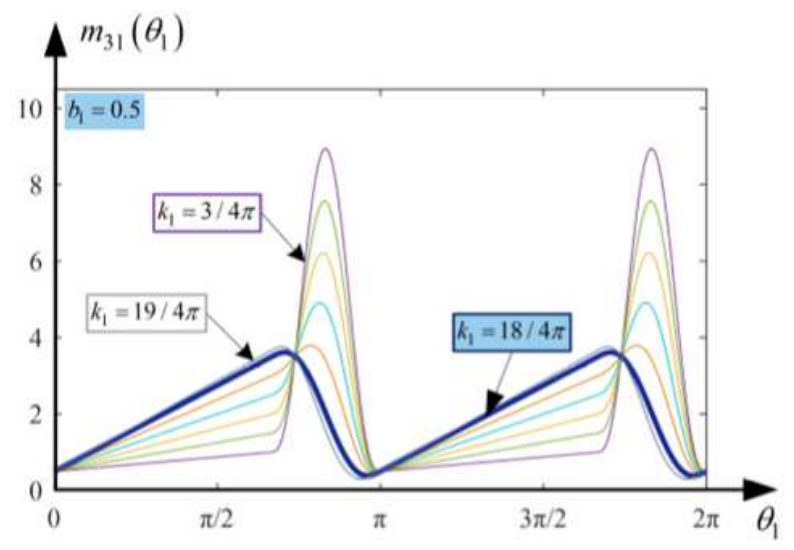

(a) The transmission ratio

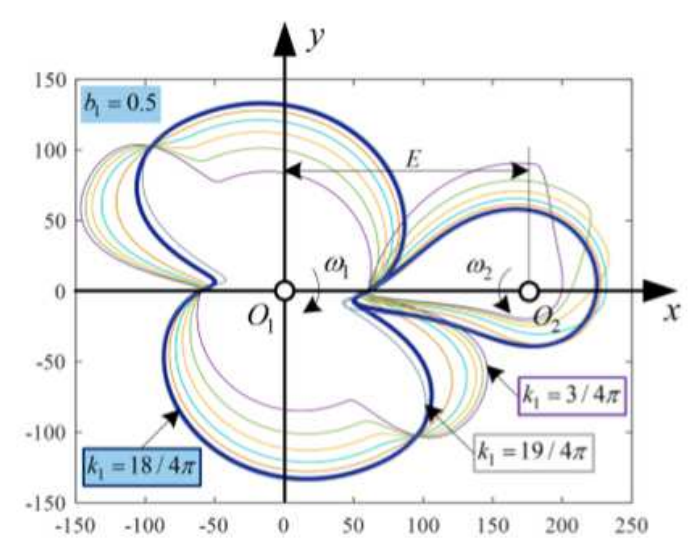

(b) The pitch curve

\section{Figure 4}

The influences of $1 \mathrm{k}$ on transmission ratio of noncircular gear pair 


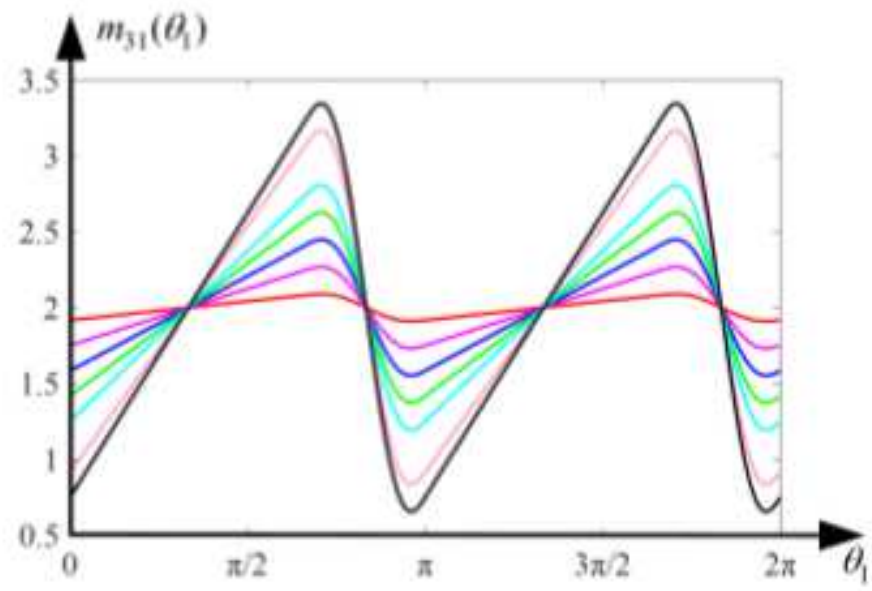

$-k_{1}=7 / 4 \pi b_{1}=17 / 12-k_{1}=5 / 4 \pi b_{1}=19 / 12-k_{1}=3 / 4 \pi b_{1}=21 / 12-k_{1}=1 / 4 \pi b_{1}=23 / 12$

$-k_{1}=15 / 4 \pi b_{1}=9 / 12-k_{1}=13 / 4 \pi b_{1}=11 / 12-k_{1}=11 / 4 \pi b_{1}=13 / 12-k_{1}=9 / 4 \pi b_{1}=15 / 12$

(a) The transmission ratio

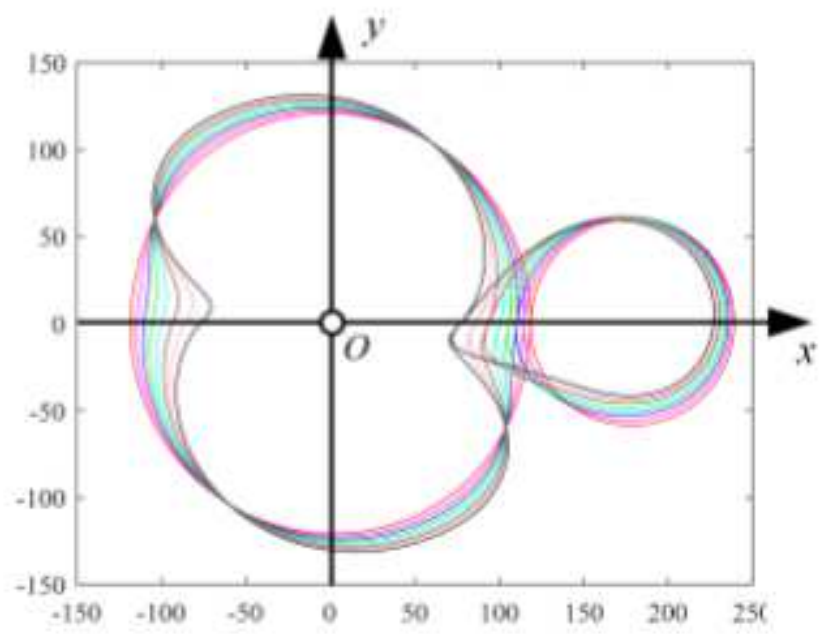

$-k_{1}=7 / 4 x b_{1}=17 / 12-k_{1}=5 / 4 * b_{1}=19 / 12-k_{1}=3 / 4 \pi b_{1}=21 / 12-k_{1}=1 / 4 \pi b_{1}=23 / 12$

$-k_{1}=15 / 4 \pi b_{1}=9 / 12 \quad k_{1}=13 / 4 \approx b_{1}=11 / 12-k_{1}=11 / 4 \pi b_{1}=13 / 12 \quad k_{1}=9 / 4 \pi b_{1}=15 / 12$

(b) The pitch curve

\section{Figure 5}

Comparisons of transmission ratio and centrode of noncircular gear pairs with different transmission ratio parameters 


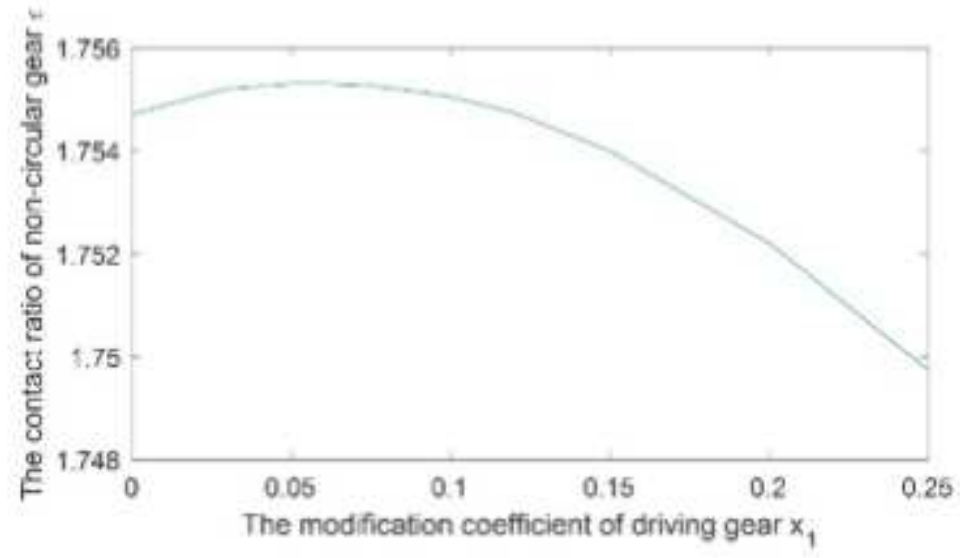

Figure 6

The influence of zero modification on the contact ratio of noncircular gear
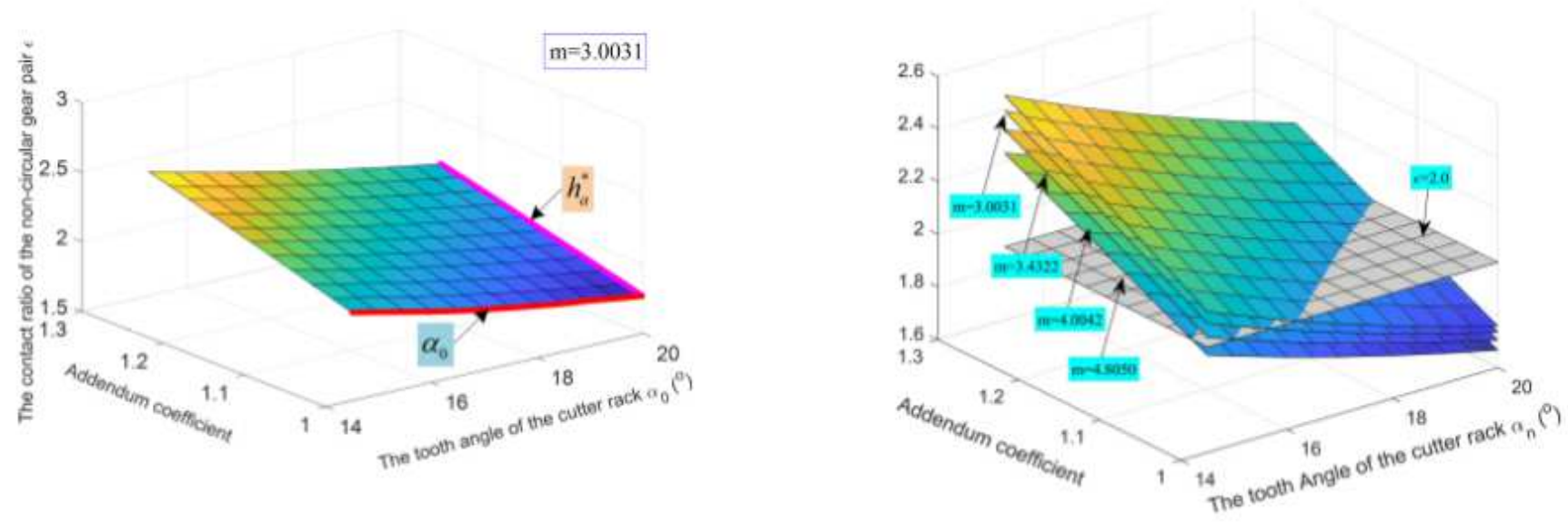

a

b

Figure 7

The influence of each parameter on the contact ratio (a) The influence of the modification coefficient and tooth profile angle of the rack cutter on the contact ratio (b) The influence of module on the contact ratio 


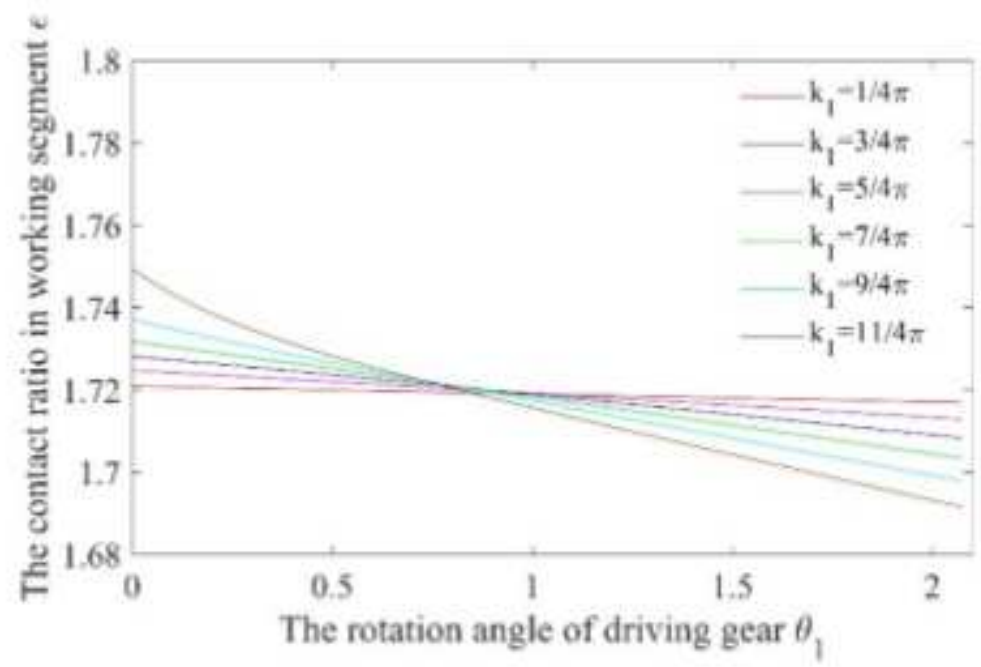

Figure 8

The influence of transmission ratio coefficient on contact ratio

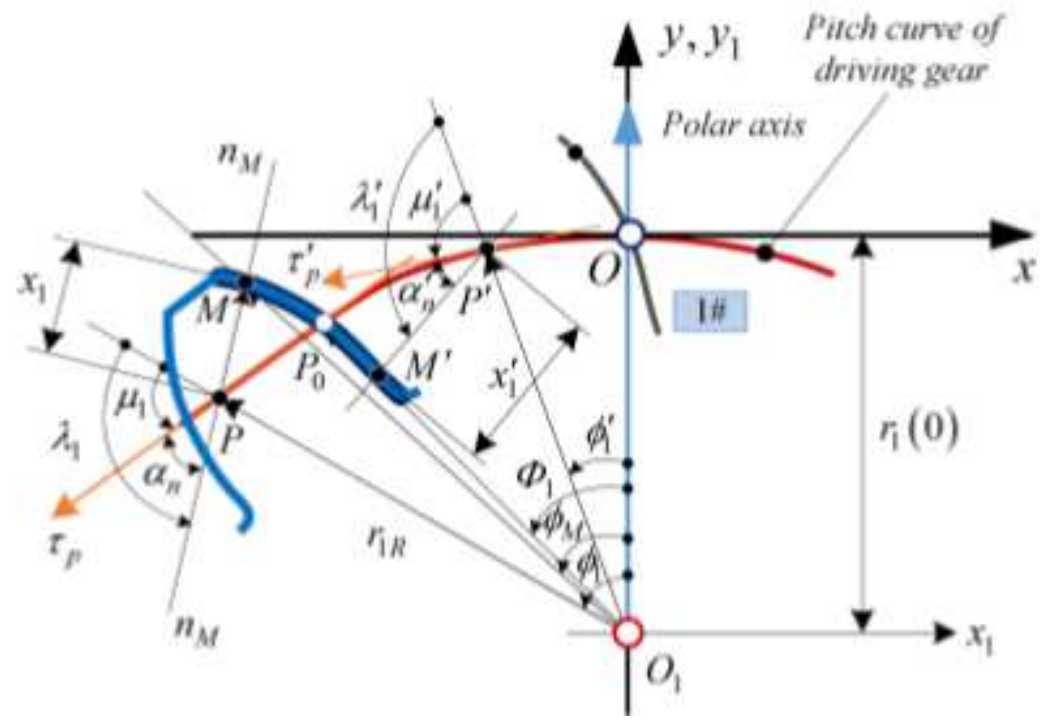

Figure 9

The analytical diagram of tooth profile of driving gear 


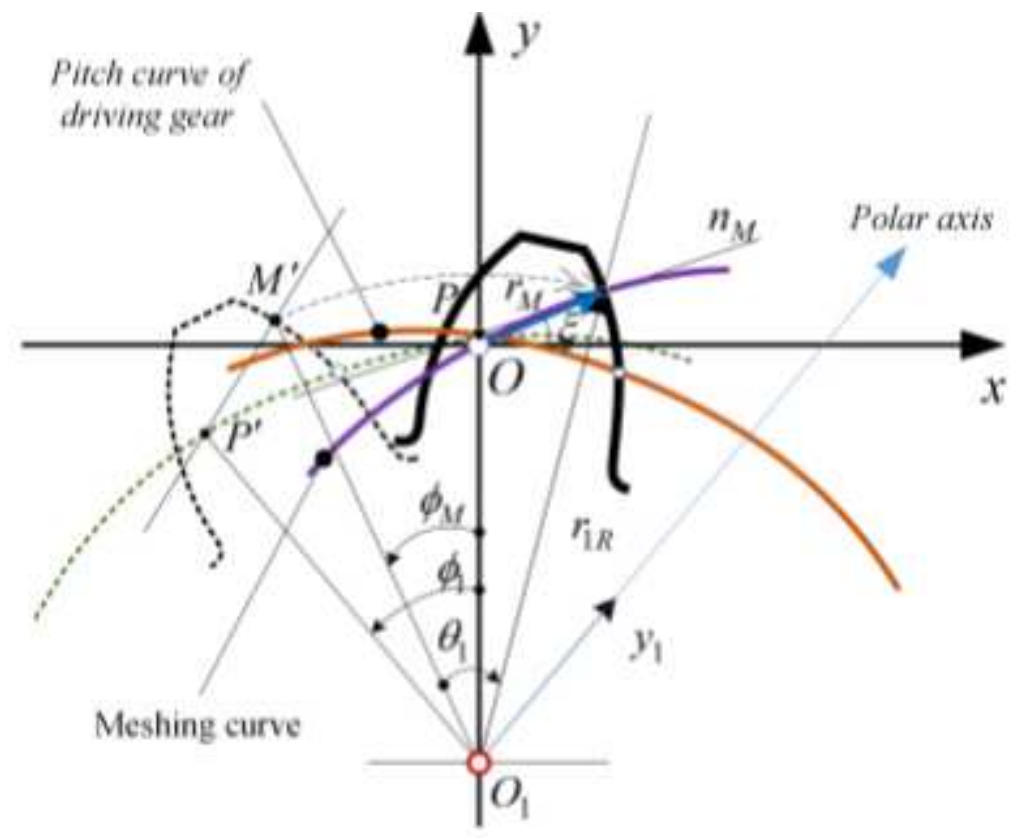

Figure 10

The analytical diagram of meshing curve of noncircular gear pair

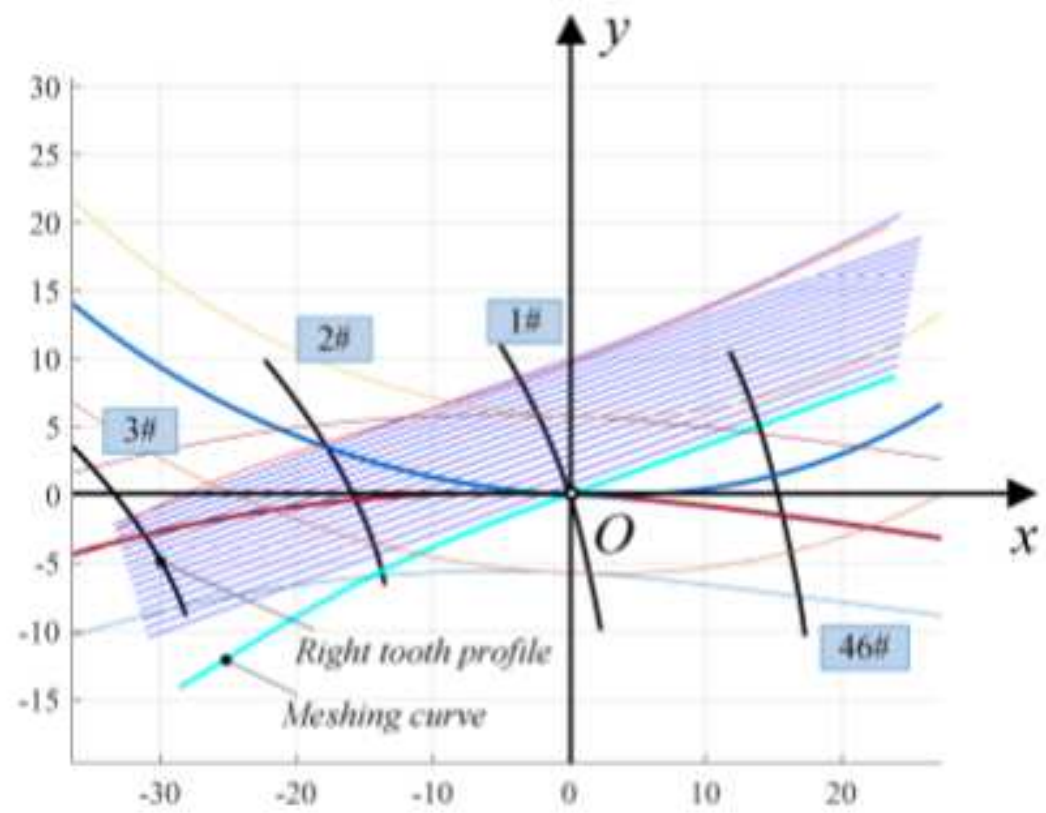

Figure 11

The theoretical results of some meshing curves of noncircular gear pair by MATLAB 


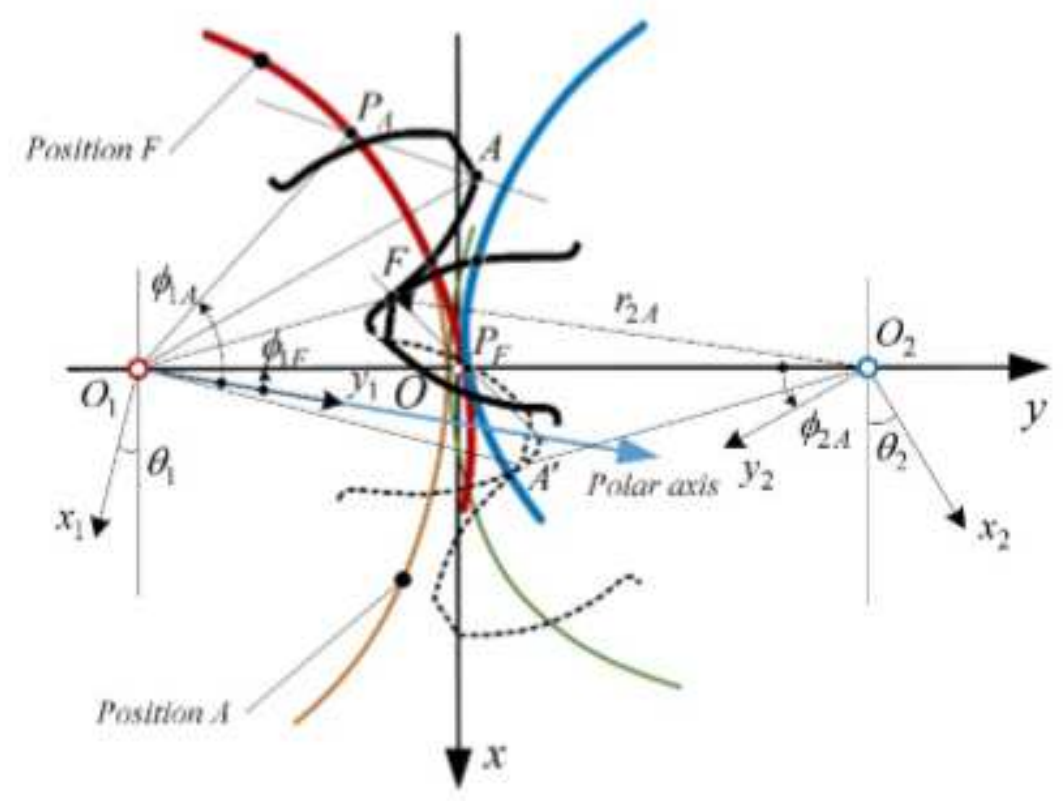

Figure 12

The analytical diagram of contact profile of driving gear and the addendum curve of driven gear

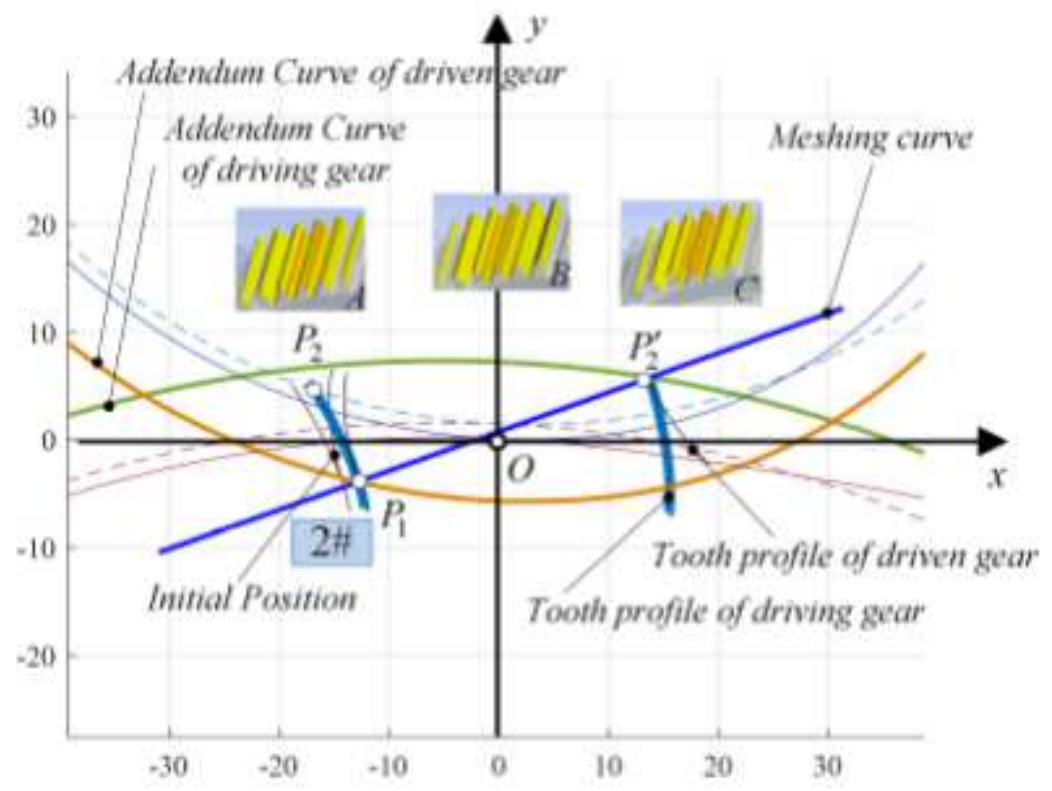

Figure 13

The 2\# theoretical contact tooth profile of driving gear by MATLAB 

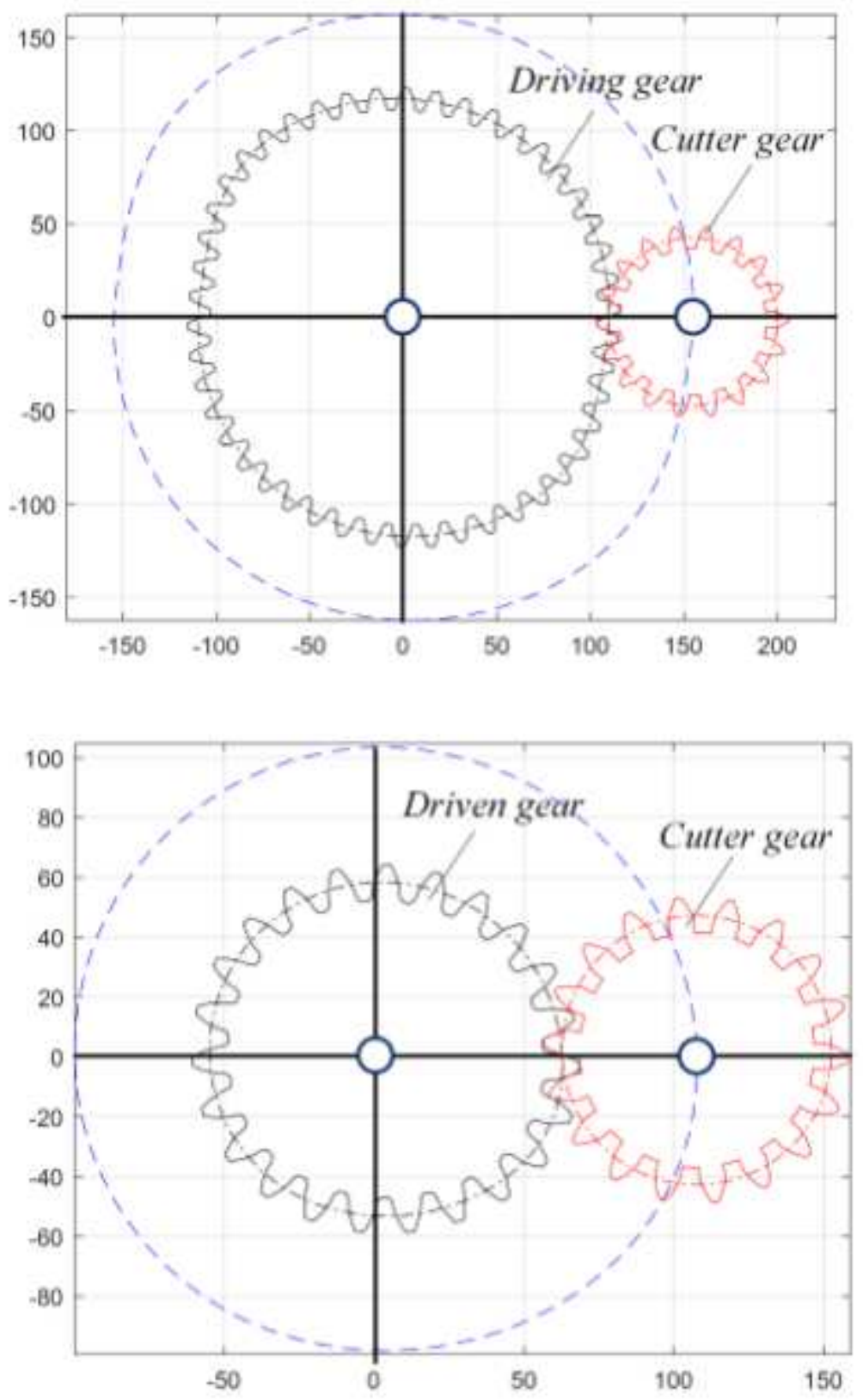

Figure 14

The tooth profile curve of noncircular gear pair with MATLAB (a) Tooth profile curve of driving gear (b) Tooth profile curve of driven gear

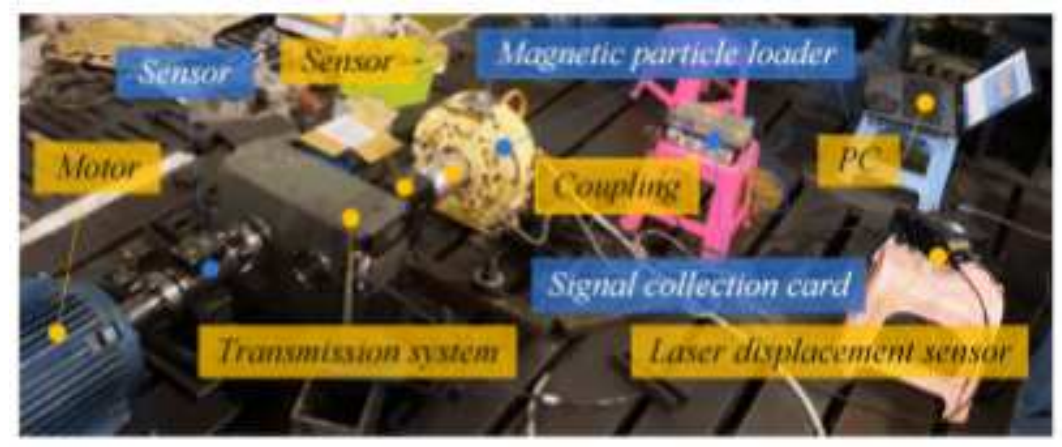


Figure 15

The experimental test platform of the noncircular gear transmission

(a) The driven noncircular gear
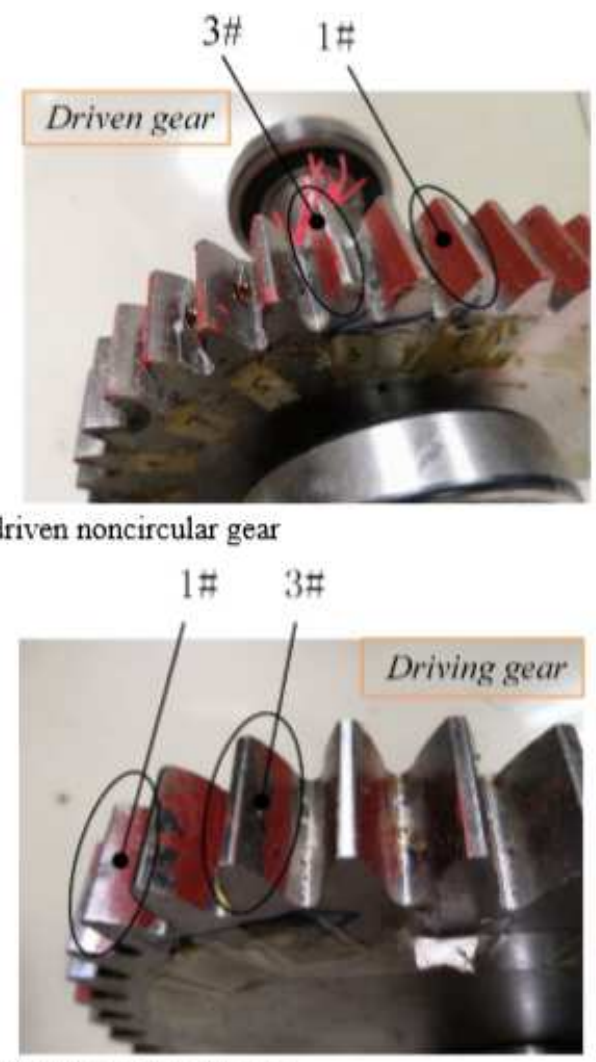

(b) The driving noncircular gear

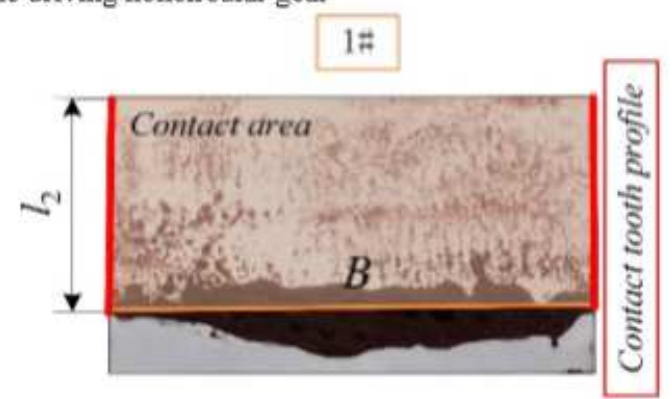

(c) The contact area of $1 \#$ teeth of driving gear

3 t

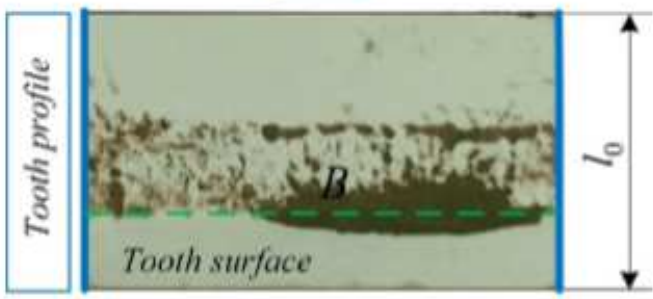

(d) The tooth surface of 3 \# teeth of driving gear

\section{Figure 16}

The length of contact profile of driving gear 


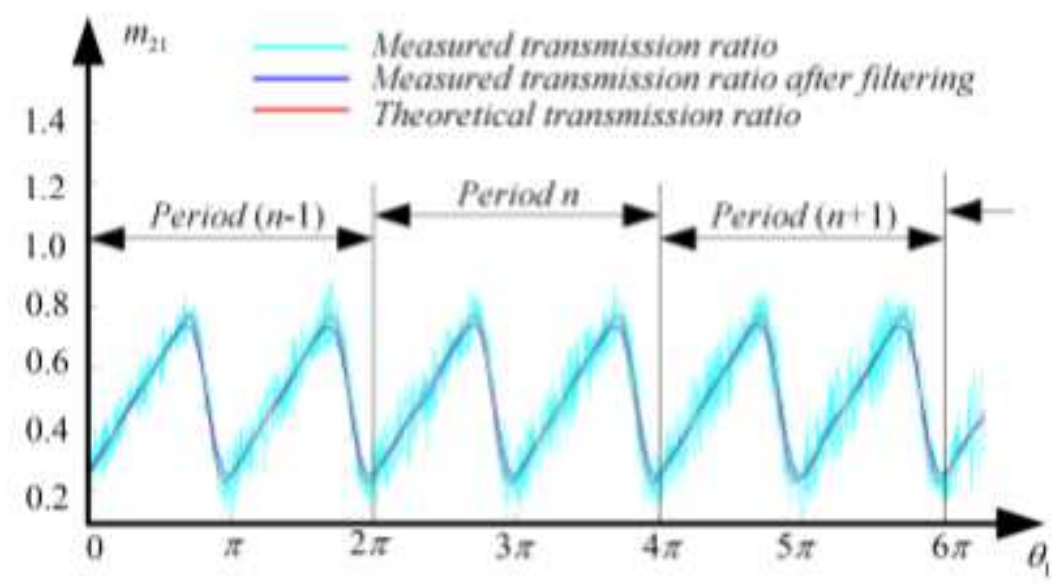

(a) The transmission ratio

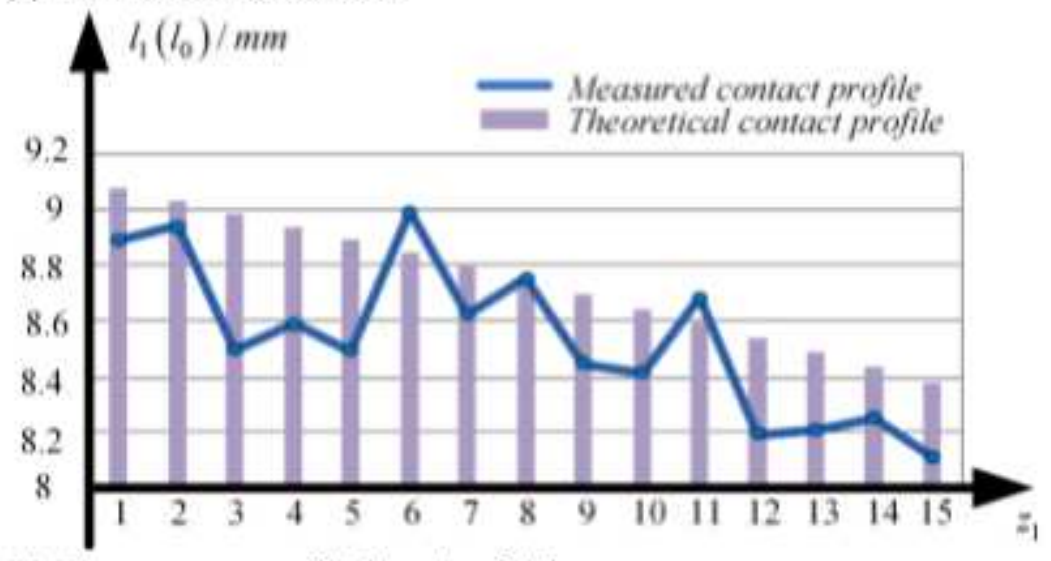

(b) The contact profile length of driven gear

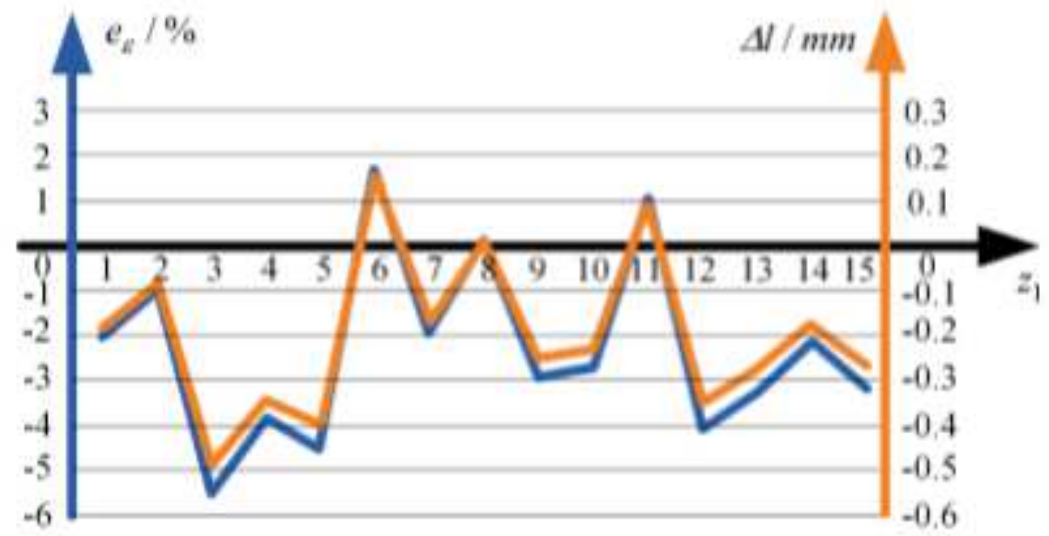

(c) The length error of contact tooth profile

\section{Figure 17}

The transmission ratio and contact profile length of the driving gear 